\title{
ANDISOLES, INCEPTISOLES Y ENTISOLES DE LA SUBCUENCA DEL RÍO PIRRÍS, REGIÓN DE LOS SANTOS, TALAMANCA, COSTA RICA ${ }^{1}$
}

\author{
Miguel Chinchilla ${ }^{2 / *}$, Rafael Mata ${ }^{* *}$, Alfredo Alvarado ${ }^{* *}$ \\ Palabras clave: Clasificación suelos, Andisoles, Inceptisoles, Entisoles, Los Santos, Talamanca. \\ Keywords: Soil classification, Andisols, Inceptisols, Entisols, Los Santos, Talamanca.
}

\section{RESUMEN}

En la subcuenca alta del río Pirrís, se describieron y clasificaron 8 perfiles de suelos derivados de cenizas volcánicas en 2 órdenes de suelos: Andisoles e Inceptisoles, subórdenes Ustands, Udands y Ustepts; grandes grupos Haplustands, Placudands, Dystrustepts y subgrupos Dystric Haplustands, Humic Haplustands, Aquic Haplustands, Typic Placudands y Andic Dystrustepts. Muchos de estos suelos, se encuentran en superficie frágiles, vulnerables a erosionarse y deslizarse. En general, estos suelos son ácidos, de baja fertilidad, con horizontes superficiales de cenizas del Holoceno, pero pueden presentar horizontes argílicos que indican discontinuidad cronológica, atribuida a litologías del Pleistoceno. Sobre terrazas aluviales recientes del Holoceno, otro grupo de 7 perfiles de suelos fueron descritos. Estos son de escaso desarrollo morfológico, con procesos de remoción desde las partes más altas, desborde y deposición de las partículas en los fondos de valle. Se clasificaron en los órdenes Entisoles e Inceptisoles, subórdenes Fluvents y Ustepts, grandes grupos Ustifluvents, Dystrustepts, Haplustepts y subgrupos Typic Ustifluvents, Fluventic Dystrustepts, Fluventic Haplustepts y Humic Dystrustepts. Las

1 Este trabajo forma parte de la tesis de maestría del primer autor.

2 Autor para correspondencia. Correo electrónico: mchinchillaa@ice.go.cr

\section{ABSTRACT}

Andisols, Inceptisols and Entisols of the Pirrís River watershed, Los Santos, Talamanca, Costa Rica. Eight soil profiles were described and classified on volcanic ash deposits at the upper Pirrís River watershed. The soils were classified as Andisols and Inceptisols of the suborders Ustands, Udands and Ustepts; at the great group level the soils were classified as Haplustands, Placudands and Dystrustepts, belonging to the subgroups Dystric Haplustands, Humic Haplustands, Aquic Haplustands, Typic Placudands and Andic Dystrustepts. The topsoil characteristics of many of these soils are fragile, vulnerable to erosion and landslides. In general, these soils are acid, of low fertility status and present recent surface horizons (Holocene), but could be underlain by argillic horizons formed during the Pleistocene. On recent alluvial terraces from the Holocene, another group of seven soil profiles were described. These show little morphological development; major soilforming processes in these positions include detachment in the highlands and deposition of particles through river flooding in the lowlands. These soils were classified in the orders Entisols and Inceptisols, suborders Fluvents y Ustepts,

\footnotetext{
* Instituto Costarricense de Electricidad, San José, Costa Rica.

** Centro de Investigaciones Agronómicas, Universidad de Costa Rica. San José, Costa Rica.
} 
texturas de los Entisoles son en gran medida moderadamente gruesas (franco arenoso) y en los Inceptisoles el contenido de arcilla es más elevado, siendo las texturas dominantes franco arcillosa, franco arcillo arenosa y arcillosa. Un tercer grupo de suelos fue descrito en un anillo alrededor de los materiales intrusivos del Mioceno al Plioceno con edad de 8 a 11 Ma, donde un metamorfismo de contacto con proceso de alteración hidrotermal de la roca preexistente formó Inceptisoles pedregosos, poco profundos, ácidos y de coloración amarillenta. Procesos de formación de suelos en esta área son la iluviación, lixiviación, lavado, formación de humus, descomposición, síntesis y erosión superficial.

\section{INTRODUCCIÓN}

En los flancos Norte, Noreste, Este y Sureste de la subcuenca del río Pirrís, existen litologías volcánicas (Formación Grifo Alto) e intrusivas (Grupo Comagmático Talamanca) y en fondos de valle sedimentos no consolidados Cuaternarios (Mora et al. 1985, Denyer y Arias 1991, ICE 2007). Las litologías de Grifo Alto (Plioceno: 1,8 a 5,0 Ma) la componen lavas basáltico andesíticas, tobas estratificadas e ignimbritas, así como de conglomerados volcaniclásticos (ICE 1979, ICE 2007). Las litologías intrusivas (Mioceno y Plioceno 1,8 a $23 \mathrm{Ma}$ ) incluyen monzonitas, monzodioritas, latiandesitas, diabasas, gabros y granodioritas (Mora et al. 1985, Kussmaul 1987). Los depósitos recientes del Cuaternario de las áreas urbanas de San Marcos de Tarrazú, Santa María y Copey de Dota, son litologías coluvio aluviales del Pleistoceno y Holoceno con composición litológica variable y edad no mayor a 1,8 Ma, (ICE 2007). Esta región ha sido sometida a la actividad volcánica, a la tectónica que levantó la Cordillera de Talamanca, a movimientos gravitacionales de ladera y a procesos de sedimentación coluvio aluvial (Mora et al. 1985). great groups Ustifluvents, Dystrustepts and Haplustepts, finally belonging to the subgroups Typic Ustifluvents, Fluventic Dystrustepts, Fluventic Haplustepts and Humic Dystrustepts. Most Entisols present coarse textures (sandy loam) while in the Inceptisols the clay content is dominant (clay loam, sandy clay loam and clayey textures). A third group of soils were described in a rim around intrusive materials of Miocene to Pleistocene origin, dated to be 8 to $11 \mathrm{Ma}$. On these metamorphic materials Inceptisols were formed, showing high rock and stone contents. Most of these soils are shallow, acid and of yellowish colors, due to the illuviation, lixiviation, humus formation, weathering and erosion dominating soil forming processes in this area.

En relación con el clima pasado de la Cordillera de Talamanca, hay evidencia de crisis climáticas. Horn (1990) señala que durante el Pleistoceno en la Cordillera existió nieve, pero que desde el Holoceno ha estado libre de hielo. Weyl (1957) fue el primero en afirmar la existencia de sistemas glaciáricos en el macizo Chirripó. Lachniet (2001) y Lachniet y Vázquez (2005) estiman que durante la época de máxima glaciación, una capa de hielo de $35-40$ km² cubrió los picos más altos de la Cordillera, lo que es indicador del enfriamiento y oscilación térmica en Talamanca.

Aunque la historia geológica de la Cordillera se remonta al Mioceno (Drummont et al. 1995), la mayoría de los suelos en esta parte del macizo son relativamente jóvenes, debido a varios factores que han posibilitado la formación de paleosoles (Harris 1971a, Driese et al. 2007). Entre los factores que coadyuvan a que los suelos sean jóvenes se pueden nombrar las erupciones de cenizas volcánicas periódicas durante el Holoceno (Harris 1971 b), la glaciación (Weyl 1957, Orvis y Horn 2005), los procesos paleonivales (Bergoing 2007), la erosión masiva durante el deshielo de los glaciares (Mora 1979, Protti 1996), las quemas periódicas de la cobertura 
vegetal (Williamson et al. 1986, Horn y Sandford 1992), que junto al relieve empinado y la elevada precipitación pluvial favorecen el desprendimiento y remoción de los suelos.

En el flanco Suroeste de la Cordillera de Talamanca los materiales erosionados depositados en forma de abanicos aluviales, son el producto de las etapas de degradación de la Cordillera de Talamanca durante los últimos estadios orogénicos y épocas de deshielo interglaciar (Mora 1979), que a su vez desarrollaron suelos más evolucionados (ICAFE 2002, Gómez y Chinchilla 2005). En la región de los Santos, las pocas áreas planas de sedimentación aluvial tienen suelos jóvenes debido al acumulo de materiales acarreados por los ríos (Mora et al. 1985) y son producto de erosión reciente.

Además de los Ultisoles descritos por Chinchilla et al. (2011 b), la subcuenca del río Pirrís tiene suelos formados de distintos materiales parentales que clasifican como Andisoles (derivados de cenizas volcánicas), Inceptisoles (formados sobre rocas ígneas e intrusivas y depósitos recientes) y Entisoles (desarrollados a partir de aluviones y en áreas erosionadas con pendientes muy fuertes).

La presencia de Andisoles en la Cordillera de Talamanca fue mencionada por Harris (1971 a, b), Holdridge et al. (1971), Otárola y Alvarado (1976), López (1978), Blaser y Camacho (1991) y van Uffelen (1993) y Solórzano (1997) y son el producto de la andolización e hidromorfismo dominantes (Kappelle y van Uffelen 2005), causantes de la pérdida de sílice, bases y de la formación de alófana (Holdridge et al. 1971, Landaeta 1977, Landaeta et al. 1978). Algunos de estos suelos fueron clasificados como Oxic Dystrandepts, Typic Dystrandepts y Typic Placandepts.

Otros autores (Holdridge et al. 1971, Alvarado et al. 1982, Sancho y Núñez 1985, ICAFECIA 2000, Gómez y Chinchilla 2005, Winowiecki 2008) mencionan la presencia en esta región de Entisoles (Typic Troporthents, Typic Ustifluvents, Andic Udifluvents) e Inceptisoles (Andic Humitropepts y Andaquepts, Ustoxic Humitropepts, Ustic Humitropepts, Typic Humitropepts,
Oxic Dystropepts, Ustic Dystropepts, Ustoxic Dystropepts, Typic Ustropepts, Typic Eutropepts y Fluventic Andic Dystrudepts). También se han descrito algunos Histosoles o suelos orgánicos (Otárola y Alvarado 1976, Blaser y Camacho 1991, van Uffelen 1993, Cubero 2002) en áreas restringidas y Espodosoles asociados a cenizas volcánicas y vegetación de páramo (Harris 1971 a, b, Widmer 1999).

El presente trabajo tiene como objetivo general caracterizar morfológica, química y físicamente los principales Andisoles, Inceptisoles y Entisoles presentes en la subcuenca del río Pirrís. Como objetivos específicos se plantearon los siguientes: 1) Clasificar a nivel de subgrupo los Andisoles, Inceptisoles y Entisoles situados aguas arriba del sitio de presa de P.H. Pirrís, 2) Describir perfiles modales desde el punto de vista morfológico, físico y químico.

\section{MATERIALES Y MÉTODOS}

Los métodos de cartografiado, análisis químicos y físicos en el laboratorio están descritos en Chinchilla et al. (2011 a). El muestreo de suelos se realizo de acuerdo con el USDA-NRCS (2002). La clasificación de los suelos con el Soil Survey Staff (2006). Se uso como Sistema de Información Geográfica el Arc-View, versión 3.3. Para el cartografiado de los suelos en superficies con deposiciones volcánicas se utilizaron 8 perfiles de los cuales 5 son descritos por el ICE (2006), 2 de Sancho y Núñez (1985) y 1 de Solórzano (1997). En las superficies recientes aluviales, se conto con 7 perfiles: 2 del ICAFE-CIA (2000), 4 de Sancho y Núñez (1985) y 1 del ICE (2006). Las superficies asociadas a intrusivos se tuvieron 2 perfiles: ICE (2007) y Sancho y Núñez (1985).

\section{RESULTADOS Y DISCUSIÓN}

\section{Suelos derivados de cenizas volcánicas de la Cordillera de Talamanca}

1. Generalidades: La génesis de esta unidad edáfica está influenciada principalmente 
por el material parental (cenizas volcánicas), las condiciones climáticas de la zona y el tiempo relativamente corto desde que estas cenizas se depositaron. La mayoría de los suelos son profundos y clasifican como Dystric Haplustands, con pequeñas áreas de Humic y Aquic Haplustands y en un caso Andic Dystrustepts (Figura 1). En el Cuadro 1 se muestra el símbolo, área, clasificación taxonómica de los suelos formados a partir de cenizas volcánicas. En la génesis de algunos de estos suelos hay un fuerte grado de erosión sufrida, perdiéndose gran parte del horizonte superficial de cenizas volcánicas recientes. Estos suelos presentan texturas moderadamente gruesas, lo que favorece el lavado de bases y por ende las condiciones dístricas en el horizonte superficial, además previenen la formación de cantidades apreciables de alófana.
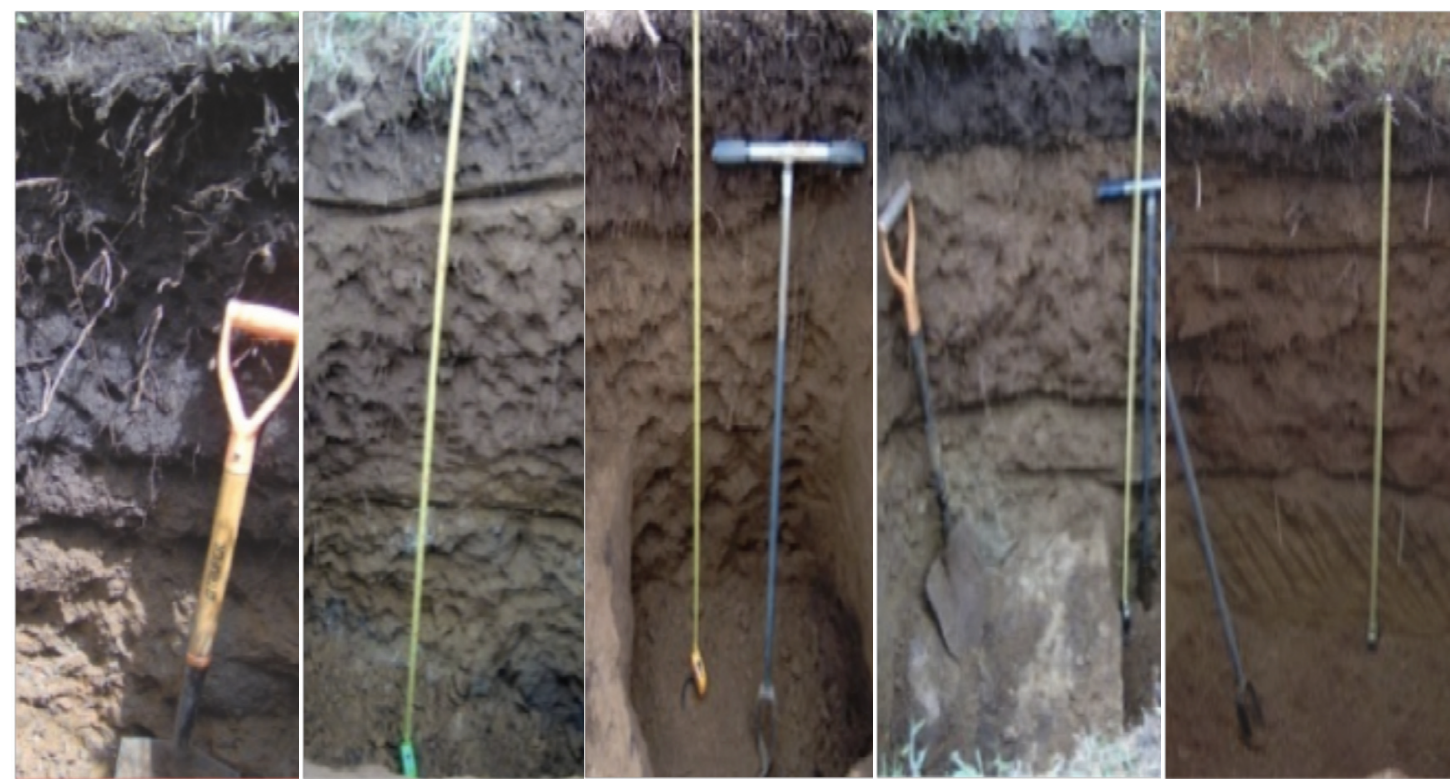

Fig.1. Suelos derivados de cenizas volcánicas de la Cordillera de Talamanca. a. Perfil 34 La Cima: Aquic Haplustands. b. Perfil 36, La Cima: Dystric Haplustands. c. Perfil 37 Quebradillas: Dystric Haplustands. d. Perfil 51 Trinidad: Andic Dystrustepts e. Perfil 52 Canet: Dystric Haplustands. 
Cuadro 1. Clasificación de los suelos derivados de cenizas volcánicas en la Cordillera de Talamanca.

\begin{tabular}{|c|c|c|c|c|c|c|}
\hline \multirow[b]{2}{*}{$\begin{array}{c}\text { Unidades cartográficas } \\
\text { (Símbolo) }\end{array}$} & \multicolumn{2}{|c|}{ Área } & \multicolumn{4}{|c|}{ Taxonomía } \\
\hline & ha & $\begin{array}{l}\% \text { área } \\
\text { estudio }\end{array}$ & Orden & Suborden & Gran Grupo & Subgrupo \\
\hline $\begin{array}{l}\text { Consociación } \\
\text { Cedral Trinidad } \\
\text { (Ce-Tri) }\end{array}$ & 2487 & 10 & $\begin{array}{l}\text { Andisoles } \\
\text { Andisoles }\end{array}$ & $\begin{array}{l}\text { Ustands } \\
\text { Udands }\end{array}$ & $\begin{array}{l}\text { Haplustands } \\
\text { Placudands }\end{array}$ & $\begin{array}{l}\text { Dystric Haplustands } \\
\text { Typic Placudands }\end{array}$ \\
\hline $\begin{array}{l}\text { Asociación } \\
\text { Trinidad - Salsipuedes } \\
\text { (Tri-Sa) }\end{array}$ & 1482 & 6 & $\begin{array}{l}\text { Andisoles } \\
\text { Inceptisoles }\end{array}$ & $\begin{array}{l}\text { Ustands } \\
\text { Ustepts }\end{array}$ & $\begin{array}{l}\text { Haplustands } \\
\text { Dystrustepts }\end{array}$ & $\begin{array}{l}\text { Dystric Haplustands } \\
\text { Andic Dystrustepts }\end{array}$ \\
\hline $\begin{array}{l}\text { Asociación } \\
\text { Cañón - La Cima } \\
(\mathrm{Ca}-\mathrm{Ci})\end{array}$ & 205 & 1 & $\begin{array}{l}\text { Andisoles } \\
\text { Andisoles }\end{array}$ & $\begin{array}{l}\text { Ustands } \\
\text { Udands }\end{array}$ & $\begin{array}{l}\text { Haplustands } \\
\text { Placudands }\end{array}$ & $\begin{array}{l}\text { Humic Haplustands } \\
\text { Aquic Haplustands } \\
\text { Typic Placudands }\end{array}$ \\
\hline $\begin{array}{l}\text { Asociación } \\
\text { Cerro Vueltas } \\
\text { (Vue) }\end{array}$ & 2300 & 9 & $\begin{array}{l}\text { Andisoles } \\
\text { Inceptisoles }\end{array}$ & $\begin{array}{l}\text { Ustands } \\
\text { Ustepts }\end{array}$ & $\begin{array}{l}\text { Haplustands } \\
\text { Dystrustepts }\end{array}$ & $\begin{array}{l}\text { Dystric Haplustands } \\
\text { Andic Dystrustepts }\end{array}$ \\
\hline
\end{tabular}

2. Morfología: Se determinó que los Dystric y Humic Haplustands presentan una secuencia de horizontes $\mathrm{A} / \mathrm{Bw} / \mathrm{BC}, \mathrm{A} / \mathrm{AB} / \mathrm{Bw} 1 / 2 \mathrm{Bt} 1, \mathrm{~A} /$ $\mathrm{AB} / 2 \mathrm{Bt} 1, \mathrm{~A} / \mathrm{AB} / \mathrm{Bw}$; los Aquic Haplustands $\mathrm{A} /$ Bt1/Bg2/C y los Andic Dystrustepts A/Bw/BC/C (Cuadro 2). El horizonte A puede ser delgado $(10 \mathrm{~cm})$ o alcanzar grosores importantes $(55 \mathrm{~cm})$. Son suelos oscuros en superficie debido a su contenido de materia orgánica y a la abundancia de minerales básicos de color oscuro; la materia orgánica tiende a acumularse en el régimen de temperatura isomésico de la unidad edáfica. En algunos casos, el horizonte $\mathrm{Bw}$ presenta una coloración rojiza y amarilla, lo que demuestra la acumulación de cantidades apreciables de óxidos de hierro en diferentes estados de hidratación; en otros procesos, el hierro puede formar horizontes plácicos dando origen a inclusiones de Typic Placudands. Cuando la ceniza volcánica se ha erosionado, los suelos de esta unidad pueden presentar un horizonte $\mathrm{Bt}$, que coincide con lo reportado por Mata y Ramírez (1999) para algunas áreas de cenizas volcánicas de Costa Rica.

3. Distribución del tamaño de partículas: Los Haplustands tienen texturas moderadamente gruesas (franco arenoso) y medianas (francas) en superficie (Cuadro 3). En los horizontes B, aumentan los contenidos de arcilla y las texturas son moderadamente fina y fina (franco arcilloso, arcilloso y arcillo arenoso). El horizonte BC puede ser moderadamente grueso a fino (franco arenoso, franco arcilloso, arcillo arenoso) y el horizonte $\mathrm{C}$ es de textura fina (arcillo arenosa).

4. Densidad aparente (Da): La Da medida a $33 \mathrm{KPa}$ de retención de humedad en suelos con propiedades ándicas es por definición menor a $0,90 \mathrm{Mg} \cdot \mathrm{m}^{-3}$. Indiferente del horizonte, la Da de los suelos bajo estudio osciló entre 0,6 y 1,3 $\mathrm{Mg} \cdot \mathrm{m}^{-3}$, lo que denota la poca influencia de la ceniza volcánica o discontinuidad litológica en los horizontes sub-superficiales (Cuadro 3). Los 
Cuadro 2. Características morfológicas de los suelos derivados de cenizas volcánicas en la Cordillera de Talamanca.

\begin{tabular}{|c|c|c|c|c|}
\hline $\begin{array}{l}\text { Clasificación } \\
\text { taxonómica }\end{array}$ & Horizonte & $\begin{array}{l}(\mathrm{cm}) \\
\text { Prof. }\end{array}$ & Color Munsell & \\
\hline & Ap & $0-8$ & Negro $*$ & $10 \mathrm{YR} 2 / 1$ \\
\hline Humic & A2 & $8-24$ & Negro & $10 \mathrm{YR} 2 / 1$ \\
\hline Haplustands & Bw1 & $24-51$ & Pardo grisáceo muy oscuro & $10 \mathrm{YR} 3 / 2$ \\
\hline \multirow[t]{2}{*}{ (perfil 11) } & $\mathrm{Bw} 2$ & $51-83$ & Pardo oscuro & $10 \mathrm{YR} 3 / 3$ \\
\hline & $\mathrm{BC}$ & $83-115$ & Pardo grisáceo oscuro & 7,5 YR 3,5/2 \\
\hline Dystric & A & $0-30$ & Pardo rojizo oscuro & $5 \mathrm{YR} 3 / 2,5$ \\
\hline Haplustands & $\mathrm{AB}$ & $30-64$ & Pardo fuerte & $10 \mathrm{YR} 4 / 6$ \\
\hline \multirow[t]{2}{*}{ (perfil 14) } & Bw1 & $64-85$ & Pardo fuerte & 7,5 YR 5/6 \\
\hline & $2 \mathrm{Bt} 1$ & $85-150$ & Pardo fuerte & 7,5 YR 5/8 \\
\hline Dystric & A & $0-21$ & Pardo & 7,5 YR $4 / 4$ \\
\hline Haplustands & $\mathrm{AB}$ & $21-52$ & Pardo fuerte & 7,5 YR 4/6 \\
\hline \multirow[t]{2}{*}{ (perfil 15) } & Bw1 & $52-143$ & Pardo fuerte & 7,5YR 5/7 \\
\hline & Bw2 & $143-200$ & Pardo amarillento & 10 YR 5/7 \\
\hline & Ap & $0-19$ & Negro & $10 \mathrm{YR} 1 / 1$ \\
\hline Aquic & A2 & $19-55$ & Negro & $10 \mathrm{YR} 2 / 1$ \\
\hline Haplustands & Bt1 & $55-90$ & Pardo amarillento oscuro & $10 \mathrm{YR} 4 / 6$ \\
\hline \multirow[t]{2}{*}{ (perfil 34) } & $\mathrm{Bg} 2$ & $90-108$ & Gris parduzco claro $(50 \%) * *$ & 10 YR 6/2 (50\%) \\
\hline & $\mathrm{C}$ & $108-140$ & Pardo amarillento oscuro $* * *$ & 10 YR 4/8 (60\%) \\
\hline Dystric & Ap & $0-21$ & Pardo muy oscuro $* * * *$ & $10 \mathrm{YR} 2 / 2$ \\
\hline Haplustands & $\mathrm{Bw}$ & $21-80$ & Pardo amarillento oscuro & $10 \mathrm{YR} 3 / 4$ \\
\hline (perfi 36) & $\mathrm{BC}$ & $80-120$ & Pardo amarillento & $10 \mathrm{YR} 5 / 6$ \\
\hline Dystric & Ap & $0-13$ & Negro & $10 \mathrm{YR} 2 / 1$ \\
\hline Haplustands & $\mathrm{AB}$ & $13-45$ & Pardo oscuro & $10 \mathrm{YR} 3 / 3$ \\
\hline (perfi 37) & Bt1 & $45-140$ & Pardo amarillento oscuro & $10 \mathrm{YR} 4 / 6$ \\
\hline Andic & Ap & $0-24$ & Pardo oscuro & 7,5 YR $3 / 3$ \\
\hline Dystrustepts & Bw1 & $24-75$ & Pardo & 7,5 YR 4/4 \\
\hline \multirow[t]{2}{*}{ (perfil 51) } & $\mathrm{BC}$ & $75-108$ & Pardo intenso & 7,5 YR 4/6 \\
\hline & $\mathrm{C}$ & $108-150$ & Pardo amarillento & 10 YR 5/6 \\
\hline Dystric & Ap & $0-15$ & Pardo muy oscuro & 7,5 YR 2,5/2 \\
\hline Haplustands & $\mathrm{AB}$ & $15-35$ & Pardo rojizo & $5 \mathrm{YR} 4 / 4$ \\
\hline \multirow[t]{2}{*}{ (perfil 52) } & Bw1 & $35-97$ & Rojo amarillento & $5 \mathrm{YR} 4 / 6$ \\
\hline & $2 \mathrm{Bt}$ & $97-120$ & Pardo amarillento oscuro & $10 \mathrm{YR} 4 / 4$ \\
\hline
\end{tabular}

*10 YR 5/8 Pardo amarillento (5\%).

**10 YR 4/4 Pardo amarillento oscuro; 5 YR 5/8 rojo amarillento (10\%); 2,5 YR 4/6 Rojo (10\%).

***5 YR 5/6 Rojo amarillento (20\%); 5 YR 5/2 Gris rojizo (10\%); 10 YR 1/1 Negro (10\%).

**** 10 YR 4/1 Gris Oscuro (10\%). 
Cuadro 3. Características físicas de los suelos derivados de cenizas volcánicas en la Cordillera de Talamanca.

\begin{tabular}{|c|c|c|c|c|c|c|c|c|c|}
\hline \multirow{2}{*}{$\begin{array}{l}\text { Clasificación } \\
\text { taxonómica }\end{array}$} & \multirow[t]{2}{*}{ Horizonte } & \multirow{2}{*}{$\begin{array}{l}\text { Prof. } \\
(\mathrm{cm})\end{array}$} & \multicolumn{3}{|c|}{ Textura (\%) } & \multirow{2}{*}{$\begin{array}{c}\text { Clase } \\
\text { Textural }\end{array}$} & \multirow{2}{*}{$\begin{array}{c}\mathrm{Mg} \cdot \mathrm{m}^{-3} \\
\text { D. } \\
\text { aparente }\end{array}$} & \multirow{2}{*}{$\begin{array}{l}\mathrm{Mg} \cdot \mathrm{m}^{-3} \\
\text { D. real }\end{array}$} & \multirow{2}{*}{$\begin{array}{c}\% \\
\text { Porosidad }\end{array}$} \\
\hline & & & Arena & Limo & Arcilla & & & & \\
\hline & $\mathrm{Ap}$ & $0-8$ & 61 & 26 & 13 & $\mathrm{Fa}$ & nd & nd & nd \\
\hline Humic & $\mathrm{A} 2$ & $8-24$ & 54 & 29 & 17 & $\mathrm{Fa}$ & nd & nd & nd \\
\hline Haplustands & Bwl & $24-51$ & 40 & 26 & 34 & FA & nd & nd & nd \\
\hline \multirow[t]{2}{*}{ (perfil 11) } & Bw2 & $51-83$ & 34 & 27 & 39 & FA & nd & nd & nd \\
\hline & $\mathrm{BC}$ & $83-115$ & 40 & 26 & 34 & FA & nd & nd & nd \\
\hline Dystric & $\mathrm{A}$ & $0-30$ & 57 & 35 & 8 & $\mathrm{Fa}$ & nd & 2,0 & nd \\
\hline Haplustands & $\mathrm{AB}$ & $30-64$ & 56 & 24 & 20 & $\mathrm{Fa}$ & nd & 2,1 & nd \\
\hline \multirow[t]{2}{*}{ (perfil 14) } & Bw1 & $64-85$ & 39 & 18 & 43 & A & nd & 2,4 & nd \\
\hline & $2 \mathrm{Bt} 1$ & $85-150$ & 35 & 12 & 53 & A & nd & 2,3 & nd \\
\hline Dystric & $\mathrm{A}$ & $0-21$ & 57 & 28 & 15 & $\mathrm{Fa}$ & nd & 2,0 & nd \\
\hline Haplustands & $\mathrm{AB}$ & $21-52$ & 59 & 16 & 25 & FAa & nd & 1,8 & nd \\
\hline \multirow[t]{3}{*}{ (perfil 15) } & Bw1 & $52-143$ & 41 & 22 & 37 & FA & nd & 1,9 & nd \\
\hline & Bw2 & $143-200$ & 32 & 27 & 41 & A & nd & 2,2 & nd \\
\hline & Ap & $0-35$ & 63 & 28 & 9 & $\mathrm{Fa}$ & 0,9 & 2,4 & 64 \\
\hline Aquic & $\mathrm{A} 2$ & $35-55$ & 71 & 16 & 14 & $\mathrm{Fa}$ & 0,9 & 2,7 & 67 \\
\hline Haplustands & Bt1 & $55-90$ & 33 & 28 & 39 & FA & 1,3 & 2,9 & 56 \\
\hline \multirow[t]{2}{*}{ (perfil 34) } & $\mathrm{Bg} 2$ & $90-108$ & 33 & 26 & 51 & A & 1,0 & 2,4 & 59 \\
\hline & $\mathrm{C}$ & $108-140$ & nd & nd & nd & nd & nd & nd & \\
\hline Dystric & Ap & $0-21$ & 57 & 32 & 11 & $\mathrm{Fa}$ & 0,8 & 2,5 & 68 \\
\hline Haplustands & $\mathrm{Bw}$ & $21-80$ & 74 & 18 & 9 & $\mathrm{Fa}$ & 0,7 & 3,8 & 80 \\
\hline (perfil 36) & $\mathrm{BC}$ & $80-120$ & 73 & 17 & 10 & $\mathrm{Fa}$ & 0,9 & 2,7 & 68 \\
\hline Dystric & Ap & $0-13$ & 51 & 41 & 9 & $\mathrm{~F}$ & 0,7 & 2,4 & 72 \\
\hline Haplustands & $\mathrm{AB}$ & $13-45$ & 46 & 38 & 16 & $\mathrm{~F}$ & 0,8 & 2,4 & 68 \\
\hline (perfil 37) & Bt1 & $45-140$ & 23 & 28 & 49 & A & 1,1 & 2,7 & 58 \\
\hline Andic & Ap & $0-24$ & 48 & 10 & 43 & $\mathrm{Aa}$ & 0,8 & 2,4 & 68 \\
\hline Dystrustepts & Bw1 & $24-75$ & 46 & 10 & 44 & $\mathrm{Aa}$ & 0,9 & 2,7 & 69 \\
\hline \multirow[t]{2}{*}{ (perfil 51) } & $\mathrm{BC}$ & $75-108$ & 50 & 10 & 40 & $\mathrm{Aa}$ & 1,1 & 2,7 & 61 \\
\hline & $\mathrm{C}$ & $108-150$ & 61 & 31 & 8 & $\mathrm{Fa}$ & & 2,7 & \\
\hline Dystric & Ap & $0-15$ & 56 & 32 & 13 & $\mathrm{Fa}$ & 0,8 & 2,4 & 78 \\
\hline Haplustands & $\mathrm{AB}$ & $15-35$ & 54 & 31 & 15 & $\mathrm{Fa}$ & 0,6 & 2,5 & 75 \\
\hline \multirow[t]{2}{*}{ (perfil 52) } & Bw1 & $35-97$ & 40 & 20 & 40 & FA & 0,8 & 2,8 & 72 \\
\hline & $2 \mathrm{Bt}$ & $97-120$ & 34 & 15 & 51 & A & 1,2 & 2,8 & 56 \\
\hline
\end{tabular}

$\mathrm{Fa}=$ franco arenoso; $\mathrm{FA}=$ franco arcillo arenoso; $\mathrm{A}=$ arcilloso; $\mathrm{Aa}=$ arcillo arenoso; $\mathrm{nd}=$ no determinado. 
Dystric Haplustands tienen un promedio de Da de $0,8 \mathrm{Mg} \cdot \mathrm{m}^{-3}$ y el aumento con la profundidad ocurre cuando se presentan horizontes $\mathrm{Bg}$ ó $\mathrm{Bt}$ enterrados. Cuando la cobertura vegetal es de gramíneas (potreros), los valores superficiales de $\mathrm{Da}$ en el horizonte Ap $\left(0,81 \mathrm{Mg} \cdot \mathrm{m}^{-3}\right)$ son mayores que los encontrados en el horizonte $\mathrm{Bw}$ $\left(0,74 \mathrm{Mg} \cdot \mathrm{m}^{-3}\right)$, indicando el efecto de compactación causado por el pisoteo del ganado (perfil 36, La Cima), con un aumento significativo en el horizonte BC $\left(0,88 \mathrm{Mg} \cdot \mathrm{m}^{-3}\right)$ donde el contenido de grava aumenta y disminuye la materia orgánica; el efecto de compactación por efecto del pisoteo en suelos similares de Coto Brus no fue detectado por la variable Da, pero si por la resistencia a la penetración (Murillo 1996). Se encontró que entre el porcentaje de arcilla y la Da de los Dystric Haplustands existe una relación exponencial positiva e igual pero negativa con el contenido de carbón orgánico (Figura 2).
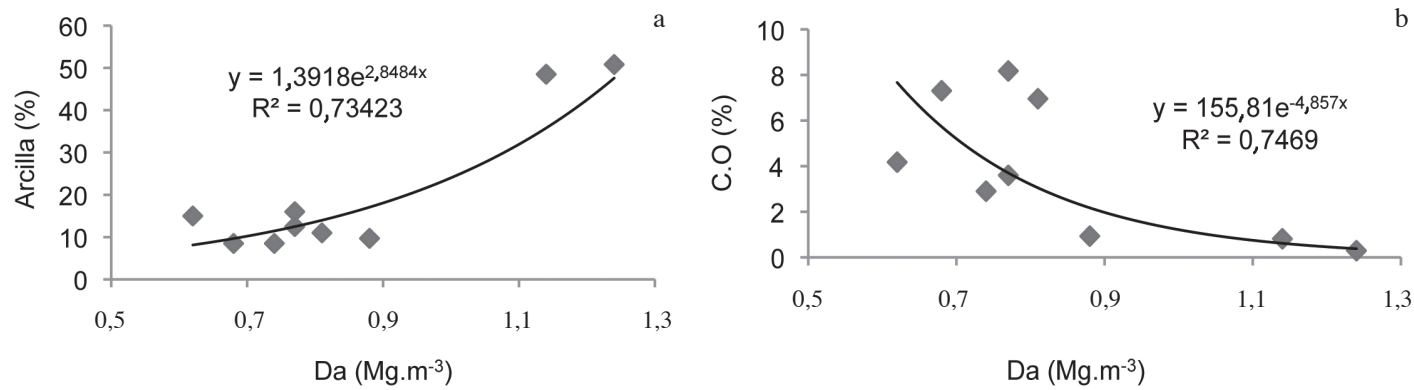

Fig. 2 Relación entre la densidad aparente y el contenido de arcilla (a) y carbón orgánico (b) en Dystric Haplustands.

5. Densidad real o de partículas (Dp): Comúnmente se asume que la Dp de los suelos es de 2,65 Mg.m ${ }^{-3}$, valor que corresponde a la densidad del cuarzo, mineral muy abundante en suelos altamente meteorizados, sin considerar que la Dp del humus de $1,37 \mathrm{Mg} \cdot \mathrm{m}^{-3}$, lo cual es de relevancia en los horizontes superficiales (Porta et al. 1994). En los suelos de la unidad influenciada por cenizas volcánicas, no ocurre una concentración importante de cuarzo sino más bien de olivinos y feldespatos asociados a altos contenidos de materia orgánica, por lo que los valores de Dp oscilaron entre 1,8 y $2,8 \mathrm{Mg} \cdot \mathrm{m}^{-3}$ (Cuadro 3). En relación con otros Andisoles de Costa Rica, los valores se encuentran en el ámbito normal (Alvarado et al. 2001), especialmente de los suelos derivados de cenizas volcánicas menos desarrollados. Los valores más bajos de Dp de los suelos estudiados se presentan en las capas superficiales como efecto de un mayor porcentaje de materia orgánica.
6. Porosidad: En los Dystric Haplustands, los porcentajes de porosidad total se encuentran entre un $80 \%$ en el horizonte $\mathrm{Bw}$ en el perfil 36 La Cima y $56 \%$ en el horizonte $2 \mathrm{Bt} 1$ del perfil 52 Bajo Canet; también se observa que la microporosidad de los horizontes B de textura fina contribuye con una cantidad de poros menor que la macroporosidad de los horizontes A de textura gruesa a media (Cuadro 3).

\section{Reacción del suelo ( $\mathrm{pH}$ en $\mathrm{H}_{2} \mathrm{O}, \mathrm{KCL}$} y NaF): El pH medido en agua en los Dystric Haplustands y en los Andic Dystrustepts osciló de 4,8 y 5,8 , valores considerados como muy fuertemente ácidos $(4,8)$ a medianamente ácidos $(5,8)$ (Cuadro 4); algo similar encontraron Otárola y Alvarado (1977) para un Andisol en la parte alta de esta unidad edáfica. En los perfiles en los que se midió el $\mathrm{pH}$ en $\mathrm{KCl}$, este siguió la misma tendencia que el $\mathrm{pH}$ en agua, solo que con valores aproximadamente menores en una 


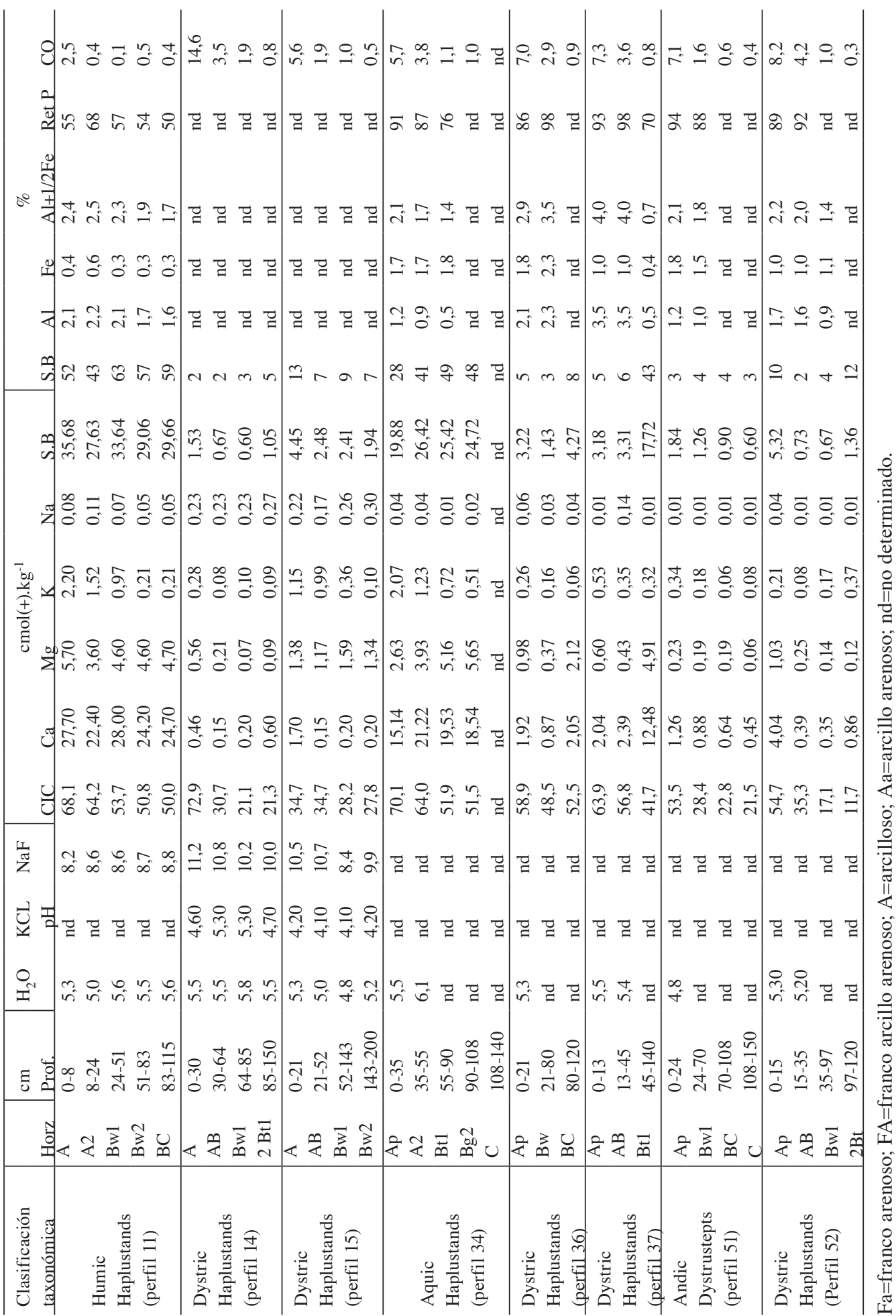


unidad. El valor de pH en $\mathrm{NaF}$ osciló entre 8,2 y 11,2 , donde disminuye con la profundidad en los Dystric Haplustands y Andic Dystrustepts. En los Humic Haplustands los valores de $\mathrm{pH}$ en agua son ligeramente superiores $(5,0-5,6)$, pero inferiores en $\mathrm{NaF}(8,2-8,8)$ a los encontrados para la mayoría de Andisoles de Costa Rica (Alvarado et al. 2001). Aparentemente, la formación de complejos órgano-minerales, permite la inactivación del Al intercambiable en estos suelos, en los cuales por la misma razón, la retención de $\mathrm{P}$ es baja.

\section{Capacidad de Intercambio de catio-} nes (CIC): Indiferentemente del horizonte, los valores de CIC dependen del tipo y la cantidad de arcilla y del contenido de materia orgánica. En los suelos estudiados el promedio de la CIC es de $30 \mathrm{cmol}(+) . \mathrm{kg}^{-1}$; los valores en el horizonte A oscilan entre 34 y $70 \mathrm{cmol}(+) \cdot \mathrm{kg}^{-1}$ y en los horizontes B entre 21 y $50 \mathrm{cmol}(+) . \mathrm{kg}^{-1}$ (Cuadro 4). La CIC más baja se encontró a $100 \mathrm{~cm}$ de profundidad, en el horizonte enterrado $2 \mathrm{Bt}$

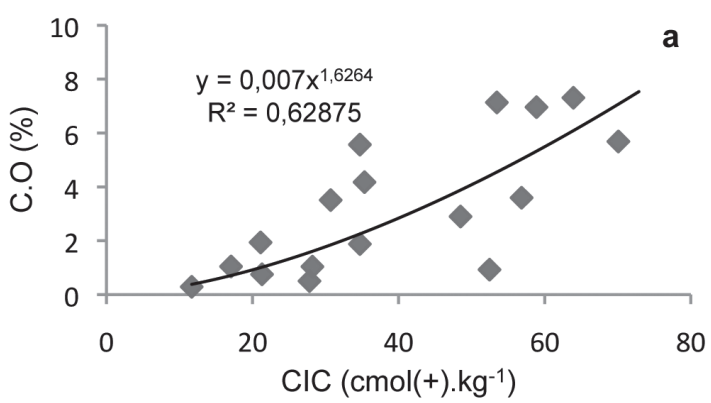

del perfil $52\left(11 \mathrm{cmol}(+) \cdot \mathrm{kg}^{-1}\right)$. En los Dystric Haplustands se determinó que cuando el contenido de carbón orgánico es bajo, los valores de CIC también son bajos y que conforme aumenta su porcentaje en el suelo, la CIC experimenta también un aumento (Figura 3a). Los datos señalan que la CIC se afecta negativamente con el tipo y cantidad de arcilla presente (Figura 3b), lo que denota que los horizontes B tienen mayor contenido de arcilla y que su mineralogía es más cristalina y con menos CIC que la de los horizontes $\mathrm{A}$, como resultado de discontinuidades litológicas encontradas. Los valores altos de CIC se asocian con arcillas poco cristalinas generadas a partir de mantos de cenizas volcánicas que cayeron en la parte alta de la cuenca, lo que genera Andisoles e Inceptisoles ándicos erosionados en el horizonte A. Los bajos valores de CIC corresponden con horizontes enterrados sobre los que se depositaron mantos de cenizas volcánicas hace cerca de 700 años.

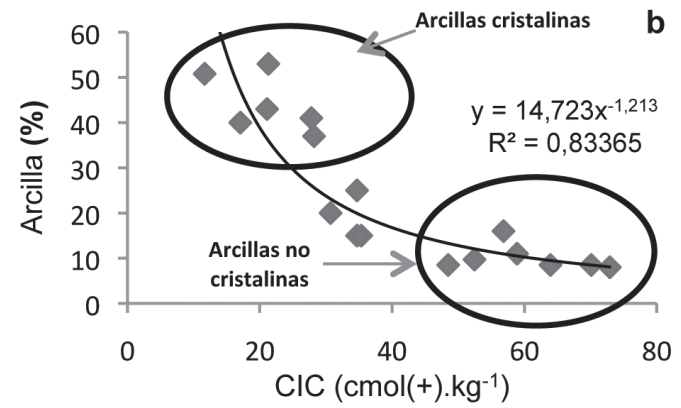

Fig. 3. Efecto del contenido de carbón orgánico (a) y de arcilla (b) sobre la CIC de los suelos derivados de cenizas volcánicas en la Cordillera de Talamanca.

9. Cationes intercambiables: Los Dystric Haplustands y Andic Dystrustepts son bajos en bases (Cuadro 4). La suma de bases oscila entre 0,60 y $5,32 \mathrm{cmol}(+) \cdot \mathrm{kg}^{-1}$ y el porcentaje de saturación de bases entre 2 y $13 \%$. El perfil 37 presenta una discontinuidad cronológica (horizonte $2 \mathrm{Bt}$ ), estrato en el que quedan atrapadas las bases lixiviadas de los horizontes superiores. Los Humic
Haplustands y Aquic Haplustands son considerados como inclusiones dentro de la unidad edáfica, por presentar contenidos importantes de $\mathrm{Ca}, \mathrm{Mg}$ y K. La suma de bases en los Humic y Aquic Haplustands oscila entre 20 y $36 \mathrm{cmol}(+) \cdot \mathrm{kg}^{-1}$ y el porcentaje de saturación de bases de 28 a $62 \%$, lo cual se puede asociar a su mayor capacidad de intercambio de cationes. 
10. Porcentaje de Hierro (Fe) y Aluminio (Al) en Oxalato Ácido: Los porcentajes de Fe y Al se usan como criterios taxonómicos en la clasificación de suelos derivados de cenizas volcánicas. Los porcentajes de aluminio e hierro extraídos en oxalato ácido en la relación $[\mathrm{Al}(\%)+1 / 2 \mathrm{Fe}(\%)$ (Oxalato acido) $] \geq 2,0 \%$ indican la presencia de suelos derivados de cenizas (Soil Taxonomy 2006). Los perfiles 11, 34, 36, 37 y 52 tienen en 35 a $80 \mathrm{~cm}$ superficiales valores de esta relación mayores que 2\%. El perfil 51 (Andic Dystrustepts) tiene fuertes propiedades ándicas en sus $24 \mathrm{~cm}$ superiores donde la suma de $\mathrm{Al}(\%)+1 / 2 \mathrm{Fe}$ (\%) es de $2,14 \%$, pero en el horizonte subyacente disminuye a $1,70 \%$, por lo que se considera que es un suelo donde los procesos erosivos han lavado las capas superficiales de cenizas (Cuadro 4).
11. Porcentaje de retención de fósforo: La relación entre la capacidad de fijación del $\mathrm{P}$ con el contenido de materia orgánica y arcilla de estos suelos con propiedades ándicas ha sido descrita por Fassbender (1980) y de acuerdo con el Soil Survey Staff (2006) estos materiales tienen una retención de fosfatos de $85 \%$ o más. En casi todos los perfiles $(11,34,36,37,51$ y 52$)$ se encontró valores de retención de $\mathrm{P}$ que oscilan entre 85 y $98 \%$, con excepción del perfil 11 donde en los primeros $50 \mathrm{~cm}$ de suelo esta variable osciló entre 54 a $68 \%$ (Cuadro 4).

La Figura 4 muestra la distribución de los suelos formados a partir de cenizas volcánicas.

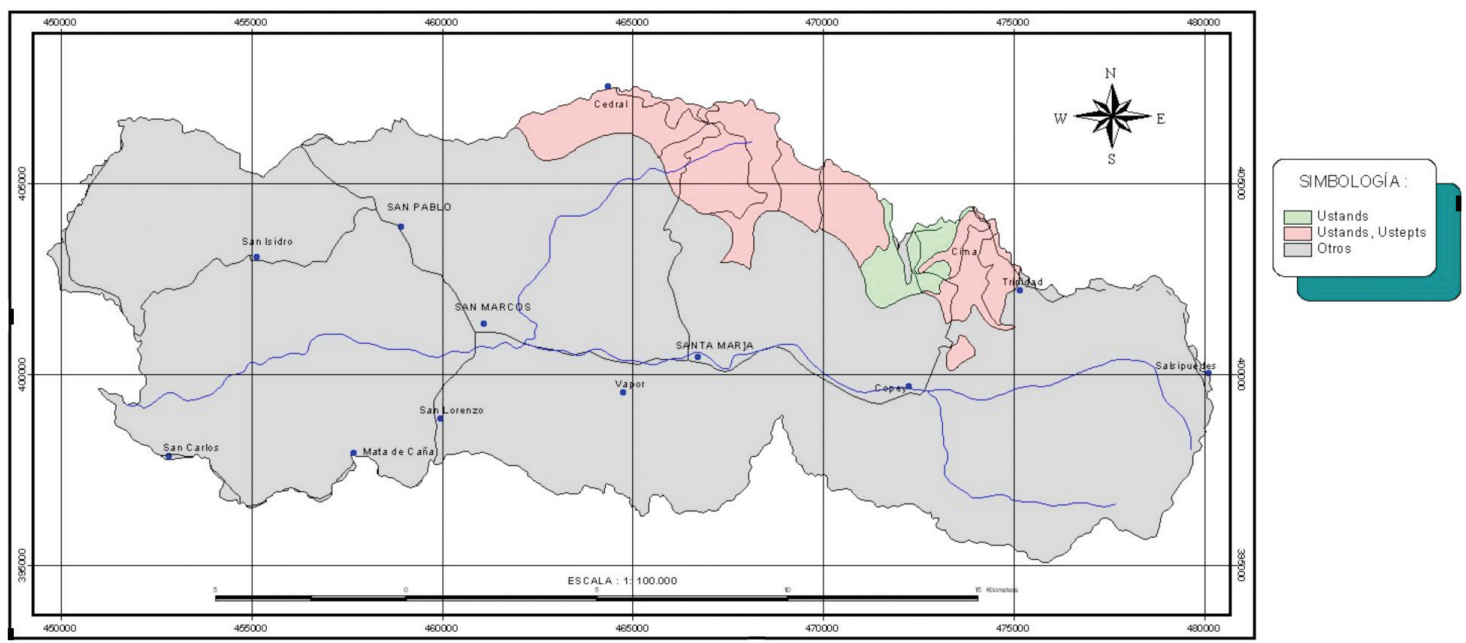

Fig. 4. Ubicación de Andisoles en la subcuenca del río Pirrís.

\section{Suelos derivados de materiales aluviales recientes}

1. Generalidades: Estos suelos se desarrollan sobre materiales que fueron depositados recientemente cerca de Santa María y Copey de Dota, principalmente en los fondos de valle y en terrazas recientes de los ríos Pirrís, Pedregoso, San Rafael y Quebrada Guzmán. A nivel de orden, se clasifican como Entisoles con epipedón úmbrico ó Inceptisoles con un horizonte cámbico. Los Entisoles son suelos con poca o no evidencia de horizontes pedogenéticos (Buol et al. 1989). El Cuadro 5 y Figura 5 presentan los suelos recientes, el símbolo, el área y clasificación taxonómica, mostrándose que son suelos superficiales a moderadamente profundos y algunos de ellos profundos. Los Typic "Andic" Ustifluvents 
Cuadro 5. Clasificación de los suelos desarrollados sobre materiales recién depositados.

\begin{tabular}{|c|c|c|c|c|c|c|}
\hline \multirow{2}{*}{$\begin{array}{l}\text { Unidades cartográficas } \\
\text { (Símbolo) }\end{array}$} & \multicolumn{2}{|c|}{ Área } & \multicolumn{4}{|c|}{ Taxonomía } \\
\hline & ha & $\%$ & Orden & Suborden & Gran Grupo & Subgrupo \\
\hline \multicolumn{7}{|l|}{ Asociación } \\
\hline San Rafael-Santa María & 302 & 1,2 & Entisoles & Fluvents & Ustifluvents & Typic "Andic" Ustifluvents \\
\hline$(\mathrm{SR}-\mathrm{SM})$ & & & Inceptisoles & Ustepts & Haplustepts & Fluventic Dystrustepts \\
\hline Asociación Copey & 191 & 0,8 & Entisoles & Fluvents & Ustifluvents & Typic "Andic" Ustifluvents \\
\hline (Co) & & & Inceptisoles & Ustepts & Dystrustepts & Humic Dystrustepts \\
\hline $\begin{array}{l}\text { Tierras Misceláneas } \\
\text { (Mis) }\end{array}$ & 248 & 1,0 & Entisoles & Fluvents & Ustifluvents & Typic Ustifluvents \\
\hline $\begin{array}{l}\text { Consociación Guzman } \\
\text { (Guz) }\end{array}$ & 89 & 0,4 & Inceptisoles & Ustepts & Haplustepts & Fluventic Haplustepts \\
\hline $\begin{array}{l}\text { Consociación Bajo San Juan } \\
(\mathrm{BSJ})\end{array}$ & 88 & 0,4 & Inceptisoles & Ustepts & Haplustepts & Fluventic Dystrustepts \\
\hline
\end{tabular}

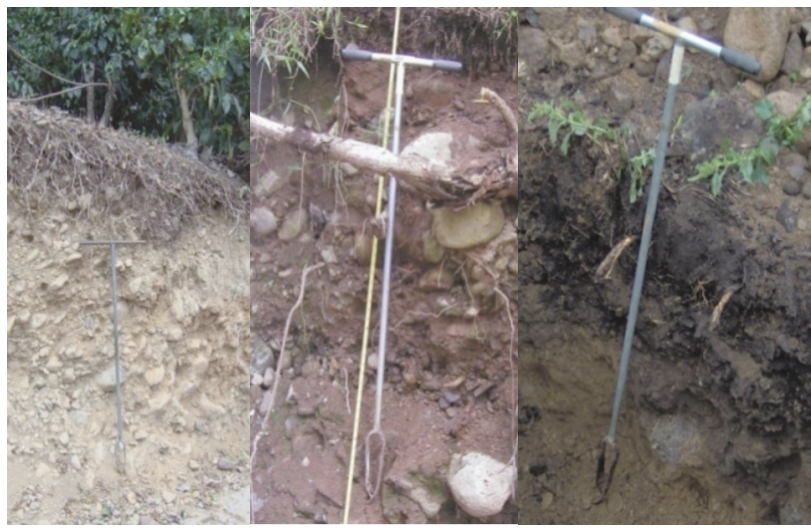

Fig. 5. Suelos desarrollados sobre materiales recién depositados. a. Perfil de suelo en Santa María de Dota: Typic Ustifluvents. b. Perfil de suelo en Pedregoso: Typic Ustifluvents. c. Perfil 35 Copey de Dota: Typic "Andic" Ustifluvents.

son superficiales, de color negro y pardo oscuro sobre pardo a pardo amarillento y pueden tener cenizas volcánicas en superficie, provenientes de los procesos erosivos de la Cordillera de Talamanca; son de textura moderadamente gruesa (franco arenosa) y mediana (franca) con una alta concentración de fragmentos angulosos en la matriz. Los suelos clasificados como Fluventic Dystrustepts y Fluventic Haplustepts son negros y pardos, moderadamente profundos a profundos, texturas moderadamente finas (franco arcillosa, franco arcillo arenosa) con horizonte cámbico y decrecimiento irregular del carbón orgánico a través del perfil. El suelo Humic Dystrustepts, es profundo, pardo, con horizonte cámbico y su textura es mediana (franca) a moderadamente fina y fina (franco arcillosa y arcillosa).

2. Morfología: Esta unidad de suelos recientes incluye los Typic "Andic" Ustifluvents como los suelos de menor desarrollo edáfico encontrados en la región; pueden tener variaciones irregulares en profundidad del contenido de carbón orgánico en el perfil y presentan secuencias morfológicos tipo $\mathrm{Ap} /$ $\mathrm{Ab} / \mathrm{C}, \mathrm{A} / \mathrm{C} / \mathrm{Ab} / 2 \mathrm{C}$ y $\mathrm{A} / \mathrm{C}$ y un horizonte $\mathrm{C}$ 
que se subdivide en C1, C2, C3. Los Fluventic Dystrustepts, Fluventic Haplustepts y Humic Dystrustepts son suelos más desarrollados genéticamente, igualmente pueden tener variaciones irregulares de carbón orgánico en el perfil y su morfología es $\mathrm{A} / \mathrm{Bw} / \mathrm{Ab} / \mathrm{C}, \mathrm{A} / \mathrm{Bw} / \mathrm{C}$ y $\mathrm{A} / \mathrm{AB} / \mathrm{Bw} / \mathrm{BC} / \mathrm{C}$. En general, el horizonte $\mathrm{A}$ en esta unidad edáfica es delgado $(13 \mathrm{~cm})$ o alcanza grosores importantes $(58 \mathrm{~cm})$, de color negro a pardo debido al contenido de materia orgánica y a minerales básicos de color oscuro. En algunos casos, su coloración amarilla y rojiza indica óxidos de hierro en diferentes estados de hidratación (Cuadro 6).

Cuadro 6. Características morfológicas de los suelos desarrollados sobre materiales depositados recientemente.

\begin{tabular}{|c|c|c|c|c|}
\hline $\begin{array}{l}\text { Clasificación } \\
\text { taxonómica }\end{array}$ & Horizonte & Prof. (cm) & Color munsell & \\
\hline \multirow{5}{*}{$\begin{array}{l}\text { Typic "Andic" Ustifluvents } \\
\text { (perfil 7) }\end{array}$} & Ap & $0-22$ & Negro & $10 \mathrm{YR} 2 / 1$ \\
\hline & $\mathrm{Ab}$ & $22-58$ & Negro & $10 \mathrm{YR} 1 / 1$ \\
\hline & $\mathrm{C} 1$ & $58-71$ & Pardo muy oscuro & $10 \mathrm{YR} 2 / 3$ \\
\hline & $\mathrm{C} 2$ & $71-114$ & Pardo amarillento & $10 \mathrm{YR} 5 / 4$ \\
\hline & $\mathrm{C} 3$ & $114-150$ & Variegado & \\
\hline \multirow{4}{*}{$\begin{array}{l}\text { Typic "Andic" Ustifluvents } \\
\text { (perfil 33) }\end{array}$} & A & $0-16$ & Pardo oscuro & 7,5 YR 3/2 \\
\hline & $\mathrm{C} 1$ & $16-30$ & Pardo amarillento & $10 \mathrm{YR} 5 / 6$ \\
\hline & $\mathrm{Ab}$ & $30-52$ & Pardo oscuro & 7,5 YR 3/2 \\
\hline & $2 \mathrm{C} 2$ & $52-80$ & Pardo amarillento & 10 YR 5/8 \\
\hline \multirow{3}{*}{$\begin{array}{l}\text { Typic "Andic" Ustifluvents } \\
\text { (perfil 35) }\end{array}$} & A & $0-13$ & Negro & 10 YR 1/1 \\
\hline & $\mathrm{C} 1$ & $13-38$ & Negro & $10 \mathrm{YR} 2 / 1$ \\
\hline & $\mathrm{C} 2$ & $38-85$ & Pardo amarillento * & $10 \mathrm{YR} 5 / 4$ \\
\hline \multirow{4}{*}{$\begin{array}{l}\text { Fluventic Dystrustepts } \\
\text { (perfil 32) }\end{array}$} & A & $0-20$ & Negro & 5 YR 2,5/1 \\
\hline & $\mathrm{Bw}$ & $20-50$ & Pardo oscuro & 7,5 YR 3/3 \\
\hline & $\mathrm{C} 1$ & $50-94$ & Pardo rojizo oscuro & $5 \mathrm{YR} 3 / 3$ \\
\hline & $\mathrm{C} 2$ & $94-145$ & Pardo rojizo oscuro & $5 \mathrm{YR} 3 / 3$ \\
\hline \multirow{4}{*}{$\begin{array}{l}\text { Andic "Fluventic" Dystrustepts } \\
\text { (perfil 3) }\end{array}$} & Ap & $0-23$ & Negro & $10 \mathrm{YR} 2 / 1$ \\
\hline & $\mathrm{Bw}$ & $23-51$ & Pardo oscuro & $10 \mathrm{YR} 3 / 3$ \\
\hline & $\mathrm{Ab}$ & $51-67$ & Pardo muy oscuro & $10 \mathrm{YR} 2 / 2$ \\
\hline & $\mathrm{C}$ & $67-150$ & Pardo & $10 \mathrm{YR} 4 / 3$ \\
\hline \multirow{5}{*}{$\begin{array}{l}\text { Fluventic Haplustepts } \\
\text { (perfil 31) }\end{array}$} & A & $0-30$ & Pardo oscuro & 7,5 YR 3/2 \\
\hline & $\mathrm{AB}$ & $30-53$ & Pardo & 7,5 YR 5/3 \\
\hline & Bw1 & $53-107$ & Pardo & 7,5 YR 4/4 \\
\hline & $\mathrm{BC}$ & $107-142$ & Pardo amarillento & $10 \mathrm{YR} 5 / 4$ \\
\hline & $\mathrm{C}$ & $142-x x$ & & \\
\hline \multirow{5}{*}{$\begin{array}{l}\text { Humic Dystrustepts } \\
\text { (perfil 28) }\end{array}$} & A & $0-33$ & Pardo amarillento oscuro & $10 \mathrm{YR} 3 / 4$ \\
\hline & $\mathrm{AB}$ & $33-65$ & Pardo amarillento oscuro & $10 \mathrm{YR} 4 / 4$ \\
\hline & Bw1 & $65-100$ & Pardo & $10 \mathrm{YR} 4 / 3$ \\
\hline & $\mathrm{Bw} 2$ & $100-135$ & Pardo & 7,5 YR 4/4 \\
\hline & $\mathrm{C}$ & $135-205$ & Pardo oscuro $(80 \%) * *$ & 7,5 YR 3/2 \\
\hline
\end{tabular}

*Pardo amarillento (10 YR 5/8 en 10\%); **Negro (10 YR 2/1 en 20\%). 
3. Distribución del tamaño de partículas: El Cuadro 7 muestra que en los Entisoles, las texturas son en gran medida moderadamente gruesas (franco arenoso), con una cantidad importante de arena que aumenta con la profundidad y contenidos de arcilla inferiores a $20 \%$. Por su parte, en los Inceptisoles, la arcilla aumenta significativamente y sus texturas son moderadamente finas a finas (franco arcillosa, franco arcillo arenosa y arcillosa) con porcentajes que alcanzan en los horizontes $\mathrm{Bw}$ de 21 a $52 \%$. Los horizontes $\mathrm{BC}$ y $\mathrm{C}$ son de textura moderadamente fina (franco arcilloso, franco arcillo arenoso) y fina (arcillosa).

Cuadro 7. Características físicas de los suelos desarrollados sobre materiales depositados recientemente.

\begin{tabular}{|c|c|c|c|c|c|c|c|c|c|}
\hline \multirow{2}{*}{$\begin{array}{l}\text { Clasificación } \\
\text { taxonómica }\end{array}$} & \multirow{2}{*}{ Horiz. } & \multirow{2}{*}{$\begin{array}{l}\mathrm{cm} \\
\text { Prof. }\end{array}$} & \multicolumn{3}{|c|}{ Textura, $\%$} & \multirow{2}{*}{$\begin{array}{l}\text { Clase } \\
\text { textural }\end{array}$} & \multicolumn{2}{|c|}{$\mathrm{Mg} \cdot \mathrm{m}^{-3}$} & \multirow{2}{*}{$\begin{array}{r}\% \\
\text { Poros. }\end{array}$} \\
\hline & & & Arena & Limo & Arcilla & & D. apar. & D. real & \\
\hline \multirow{5}{*}{$\begin{array}{l}\text { Typic "Andic" Ustifluvents } \\
\text { (perfil 7) }\end{array}$} & Ap & $0-22$ & 52 & 33 & 15 & $\mathrm{Fa}$ & 1,23 & 2,52 & 51 \\
\hline & $\mathrm{Ab}$ & $22-58$ & 43 & 37 & 21 & $\mathrm{~F}$ & 1,06 & 2,40 & 56 \\
\hline & $\mathrm{C} 1$ & $58-71$ & 47 & 33 & 19 & $\mathrm{~F}$ & 1,37 & 2,59 & 47 \\
\hline & $\mathrm{C} 2$ & $71-114$ & 65 & 24 & 11 & $\mathrm{Fa}$ & 1,44 & 2,65 & 46 \\
\hline & $\mathrm{C} 3$ & $114-150$ & 62 & 26 & 13 & $\mathrm{Fa}$ & 1,43 & 2,56 & 44 \\
\hline \multirow{4}{*}{$\begin{array}{l}\text { Typic “Andic" Ustifluvents } \\
\text { (perfil 33) }\end{array}$} & $\mathrm{A}$ & $0-16$ & 62 & 26 & 12 & $\mathrm{Fa}$ & nd & 2,35 & nd \\
\hline & $\mathrm{C} 1$ & $16-30$ & 62 & 26 & 12 & $\mathrm{Fa}$ & nd & 2,40 & nd \\
\hline & $\mathrm{Ab}$ & $30-52$ & 64 & 26 & 10 & $\mathrm{Fa}$ & nd & 2,30 & nd \\
\hline & $2 \mathrm{C} 2$ & $52-80$ & 76 & 16 & 8 & $\mathrm{Fa}$ & nd & 2,15 & nd \\
\hline \multirow{3}{*}{$\begin{array}{l}\text { Typic "Andic" Ustifluvents } \\
\text { (perfil 35) }\end{array}$} & A & $0-13$ & 68 & 22 & 10 & $\mathrm{Fa}$ & 0,52 & 2,08 & 75 \\
\hline & $\mathrm{C} 1$ & $13-38$ & 61 & 30 & 10 & $\mathrm{Fa}$ & nd & 2,36 & nd \\
\hline & $\mathrm{C} 2$ & $38-85$ & 73 & 15 & 12 & $\mathrm{Fa}$ & nd & 2,65 & nd \\
\hline \multirow{4}{*}{$\begin{array}{l}\text { Fluventic Dystrustepts } \\
\text { (perfil 32) }\end{array}$} & $\mathrm{A}$ & $0-20$ & 34 & 32 & 34 & FA & nd & 1,75 & nd \\
\hline & Bw & $20-50$ & 28 & 26 & 46 & A & nd & 2,38 & nd \\
\hline & $\mathrm{C} 1$ & $50-94$ & 38 & 22 & 40 & FA & nd & 2,27 & nd \\
\hline & $\mathrm{C} 2$ & $94-145$ & 26 & 14 & 60 & A & nd & 2,23 & nd \\
\hline \multirow{4}{*}{$\begin{array}{l}\text { Andic "Fluventic" Dystrustepts } \\
\text { (perfil 3) }\end{array}$} & Ap & $0-23$ & 42 & 26 & 32 & FA & 1,15 & 2,19 & 47 \\
\hline & $\mathrm{Bw}$ & $23-51$ & 54 & 24 & 22 & FAa & 1,13 & 2,36 & 52 \\
\hline & $\mathrm{Ab}$ & $51-67$ & 48 & 21 & 31 & FAa & 0,89 & 2,34 & 62 \\
\hline & $\mathrm{C}$ & $67-150$ & 47 & 26 & 27 & FAa & 1,40 & 2,40 & 42 \\
\hline \multirow{5}{*}{$\begin{array}{l}\text { Fluventic Haplustepts } \\
\text { (perfil 31) }\end{array}$} & A & $0-30$ & 47 & 36 & 17 & FA & nd & 2,28 & nd \\
\hline & $\mathrm{AB}$ & $30-53$ & 41 & 26 & 33 & FA & nd & 2,09 & nd \\
\hline & Bw1 & $53-107$ & 31 & 32 & 37 & FA & nd & 2,48 & nd \\
\hline & $\mathrm{BC}$ & $107-142$ & 49 & 22 & 29 & FAa & nd & 2,06 & nd \\
\hline & $\mathrm{C}$ & $142-x x$ & 35 & 30 & 35 & FA & nd & 2,19 & nd \\
\hline \multirow{5}{*}{$\begin{array}{l}\text { Humic Dystrustepts } \\
\text { (perfil 28) }\end{array}$} & A & $0-33$ & 44 & 39 & 17 & $\mathrm{~F}$ & nd & 1,74 & nd \\
\hline & $\mathrm{AB}$ & $33-65$ & 31 & 31 & 38 & FA & nd & 1,85 & nd \\
\hline & Bw1 & $65-100$ & 25 & 26 & 49 & A & nd & 2,00 & nd \\
\hline & $\mathrm{Bw} 2$ & $100-135$ & 19 & 29 & 52 & A & nd & 2,10 & nd \\
\hline & $\mathrm{C}$ & $135-205$ & 19 & 26 & 55 & A & nd & 1,70 & nd \\
\hline
\end{tabular}

$\mathrm{Fa}=$ franco arenosa $\mathrm{FAa}=$ franco arcillo arenosa $\mathrm{FA}=$ franco arcillosa; $\mathrm{A}=$ arcillosa; $\mathrm{nd}=$ no determinado. 
4. Densidad aparente (Da): Algunos suelos en esta unidad tienen una Da $\left(\mathrm{Mg}^{-3} \mathrm{~m}^{-3}\right)$ que fluctúa entre 0,52 y 1,44 (Cuadro 7). Los valores más bajos se alcanzan en los horizontes superficiales y en los enterrados, lo que puede asociarse a presencia de materiales derivados de ceniza volcánica y a mayor contenido de materia orgánica. Valores más altos se hallaron en los horizontes $\mathrm{C}(1,37$ y 1,44$)$, relacionados con la composición mineral del material del cual se forman. En los perfiles 7 y 35 clasificados como

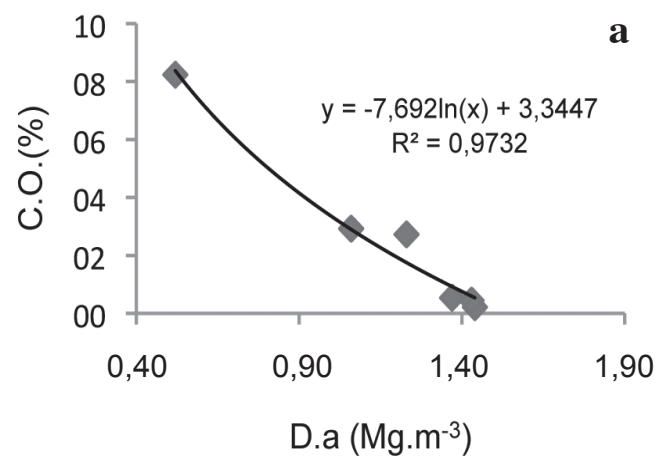

Typic "Andic" Ustifluvents, existe una relación logarítmica negativa $\left(\mathrm{R}^{2}=0,9732\right)$ entre el \% de carbón orgánico y la densidad aparente (Figura 6). Cuando se analizan en conjunto los perfiles 7, 35 (Typic "Andic" Ustifluvents) con el perfil 3 (Andic Fluventic Dystrustepts) se mantiene la relación logarítmica negativa $\left(\mathrm{R}^{2}=0,7856\right)$. No se encontró relación entre la Da y el carbón orgánico del perfil $3\left(R^{2}=0,1056\right)$ lo que puede deberse al decrecimiento irregular del carbón orgánico en profundidad.

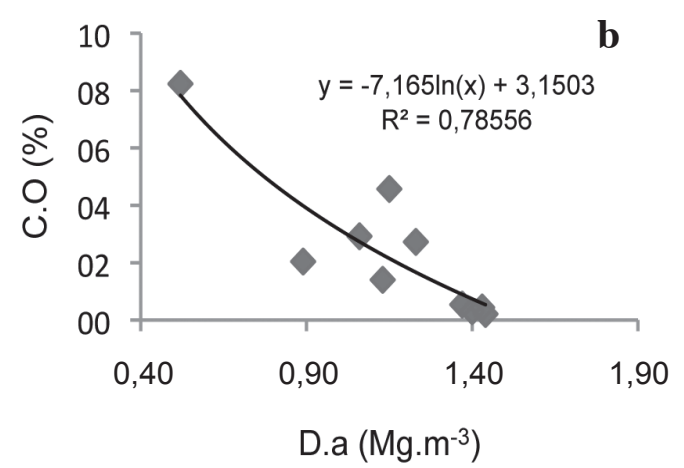

Fig. 6. Relación entre la Da y el contenido de carbón orgánico en (a) un Typic "Andic" Ustifluvents sin horizonte enterrado y (b) un Typic Andic Ustifluvents y Andic "Fluventic" Dystrustepts con horizonte enterrado.

5. Densidad real o de partículas (Dp): Los Entisoles e Inceptisoles en esta unidad son de origen aluvial y los primeros presentan una Dp $\left(\mathrm{Mg} . \mathrm{m}^{-3}\right)$ promedio de 2,42, con un máximo de 2,65 y mínimo de 2,08. En los Inceptisoles, el promedio de la $\mathrm{Dp}$ es de $2,13 \mathrm{Mg} \cdot \mathrm{m}^{-3}$, con un máximo de 2,48 y el mínimo de 1,70. La Dp varía ligeramente con la profundidad debido a diferentes eventos de sedimentación. Los valores más altos pueden estar relacionados con materiales parentales ricos en piroxenos y feldespatos y los más bajos con la deposición de materiales con características ándicas de mayor porosidad, a la materia orgánica y a la presencia de grupos órgano minerales formados entre los materiales ándicos y la materia orgánica (Cuadro 7).

6. Porosidad: En suelos desarrollados sobre materiales recientemente depositados, la porosidad oscila entre 42 a $62 \%$. Un Typic "Andic" Ustifluvents tiene una porosidad mínima de 44 y máxima de 55\% debido al mayor contenido de arena que se encuentra en este, mientras que en el Fluventic Dystrustepts estos valores están en un rango más amplio de 42 a $62 \%$ por las texturas más finas. La porosidad en profundidad muestra ligeras variaciones debido a los diferentes eventos de deposición de materiales y la presencia de horizontes A enterrados (Cuadro 7).

\section{Reacción del suelo ( $\mathrm{pH}$ en $\mathrm{H}_{2} \mathrm{O}, \mathrm{KCL}$} y NaF): Aunque gran parte de los valores del $\mathrm{pH}$ en agua se encuentran entre 5,0 y 5,6, la reacción del suelo está en un rango de muy fuertemente ácido $(\mathrm{pH} \mathrm{4,8)} \mathrm{a} \mathrm{medianamente} \mathrm{ácido}(\mathrm{pH} \mathrm{6,0)}$. Esta variación se presentó en un Entisol aluvial de Santa María de Dota, con uso de café y $\mathrm{pH}$ de 4,8 en los $20 \mathrm{~cm}$ superiores, mientras que 
un suelo de génesis similar de Copey de Dota, sembrado con mora (Rubrus spp.), el pH de 6,0 del horizonte A parece obedecer a prácticas de manejo. Los perfiles en los que se midió el pH en $\mathrm{KCl}$, tienen de 1,7 a 0,8 unidades menos al encontrado en agua. El valor de $\mathrm{pH}$ en $\mathrm{NaF}$ osciló entre 8,4 y 10,9 , considerando que los mayores a 10 indican estratos con propiedades ándicas, donde es factible en algunos suelos con un horizonte A enterrado (Cuadro 8).

8. Capacidad de Intercambio de cationes (CIC): La CIC obtenida por extracción con acetato de amonio $\left(\mathrm{NH}_{4} \mathrm{OAc} 1 \mathrm{~N}, \mathrm{pH} 7\right)$, muestra valores variables atribuidos a contenidos diferenciales de carbón orgánico entre los horizontes superficiales y subsuelo, a la variabilidad litológica de los sedimentos que sirven de material parental y a la presencia de arcillas formadas por la alteración de cenizas volcánicas depositadas y erosionas de la parte alta de la cuenca. Los Entisoles estudiados tienen una CIC promedio de $27 \mathrm{cmol}(+) \cdot \mathrm{kg}^{-1}$. En el perfil 33 la CIC es baja (7,90 a $\left.21 \mathrm{cmol}(+) \cdot \mathrm{kg}^{-1}\right)$, pero en los perfiles 7 y 35 clasificados como Typic "Andic" Ustifluvents la CIC es más alta y osciló de 27 a $74 \mathrm{cmol}(+) \cdot \mathrm{kg}^{-1}$, con valores de entre 36 y $74 \mathrm{cmol}(+) \cdot \mathrm{kg}^{-1}$ en el horizonte A y de 27 a $49 \mathrm{cmol}(+) \cdot \mathrm{kg}^{-1}$ en los horizontes C. Los Inceptisoles de esta unidad edáfica tienen una CIC promedio de $36 \mathrm{cmol}(+) \cdot \mathrm{kg}^{-1}$, con un valor máximo de $70 \mathrm{cmol}(+) \cdot \mathrm{kg}^{-1}$ y mínimo de $16 \mathrm{cmol}(+) \cdot \mathrm{kg}^{-1}$. En los Inceptisoles con CIC más baja, se tiene el perfil 32 (Fluventic Dystrustepts) ubicado cerca de Santa María de Dota (16 a 27 cmol(+). $\left.\mathrm{kg}^{-1}\right)$ y la CIC más alta (53 a $70 \mathrm{cmol}(+)$. $\mathrm{kg}^{-1}$ ) se encontró en el perfil 3 (Andic Fluventic Dystrustepts) ubicado en Bajo San Juan.

9. Cationes intercambiables: Minerales ricos en $\mathrm{Ca}, \mathrm{Mg}$ y $\mathrm{K}$, son desprendidos y transportados desde las laderas ubicadas al Sur de la cuenca media alta del Pirrís y de algunos sectores al noreste de la misma hasta depositarse en los fondos de valle de Santa María y Copey. La mayoría de los suelos en esta unidad edáfica tienen buen contenido de bases. La deficiencia de
Ca y $\mathrm{Mg}$ de los Entisoles ocurre únicamente en algunos subsuelos, mientras que en la superficie el $\mathrm{Ca}$ es medio a alto (5 a $\left.21 \mathrm{cmol}(+) \cdot \mathrm{kg}^{-1}\right)$ y el $\mathrm{Mg}$ medio a óptimo (1,15 a 3,57 $\left.\mathrm{cmol}(+) \cdot \mathrm{kg}^{-1}\right)$. El $\mathrm{K}$ en superficie es medio a alto $(0,30$ a 1,45 cmol(+). $\left.\mathrm{kg}^{-1}\right)$ y en el subsuelo medio a bajo $(0,04$ a $\left.0,43 \mathrm{cmol}(+) \cdot \mathrm{kg}^{-1}\right)$. Con excepción de algunos horizontes en los perfiles 33 y 35 con suma de bases baja (0,92 a $\left.3,36 \mathrm{cmol}(+) \cdot \mathrm{kg}^{-1}\right)$, los valores de saturación de bases en general se ubican entre 10 a $26 \mathrm{cmol}(+) \cdot \mathrm{kg}^{-1}$. Porcentajes de saturación de bases bajos y menores a $10 \%$ se presentan en el subsuelo de los perfiles 33 y 35, pero en general, el rango de saturación de bases para estos suelos es de 30 a 45\% (Cuadro 8). En los cationes cambiables, se obtuvo una relación potencial positiva entre el $\mathrm{Ca}$ y el $\mathrm{Mg}\left(\mathrm{R}^{2}=0,9291\right.$ y $\left.\mathrm{R}^{2}=0,7749\right)$ (Figura 7); esta relación probablemente indica que ambos cationes provienen de la misma fuente mineral. Los cationes intercambiables en los Inceptisoles son en general óptimos a altos en $\mathrm{Ca}$ $\left(4,3\right.$ a $\left.34 \mathrm{cmol}(+) \cdot \mathrm{kg}^{-1}\right)$, medios a óptimos a en $\mathrm{Mg}$ $\left(1,77\right.$ a $\left.5,00 \mathrm{cmol}(+) \cdot \mathrm{kg}^{-1}\right)$ y medios a altos en $\mathrm{K}$ $\left(0,20\right.$ a $\left.0,90 \mathrm{cmol}(+) \cdot \mathrm{kg}^{-1}\right)$. En estos suelos la suma de bases varía de 11 a $38 \mathrm{cmol}(+) \cdot \mathrm{kg}^{-1} \mathrm{y}$ se alcanzan porcentajes de saturación de bases de hasta 90\% en el perfil 31 (Fluventic Haplustepts). Suma de bases y porcentaje de bases bajos ocurren en el subsuelo de algunos Inceptisoles (Cuadro 8).

10. Porcentaje de Hierro (Fe) y Aluminio (Al) en Oxalato Ácido: Los porcentajes de $\mathrm{Fe}$ y Al se usan como criterios taxonómicos para suelos con influencia de cenizas volcánicas. Los perfiles 3,7 y 35 , tienen valores de esta relación mayores que $1 \%$ en superficie, por lo que se considera que son suelos que han recibido aportes superficiales de cenizas (Cuadro 8).

\section{Porcentaje de retención de fósforo:}

Existen correlaciones entre la capacidad de fijación del $\mathrm{P}$ con el contenido de materia orgánica y arcilla de los suelos con propiedades ándicas (Fassbender 1980). Se encontró valores de retención de $\mathrm{P}$ que oscilan entre 81 y $84 \%$ en suelos que presentan horizontes con capas ándicas; en 


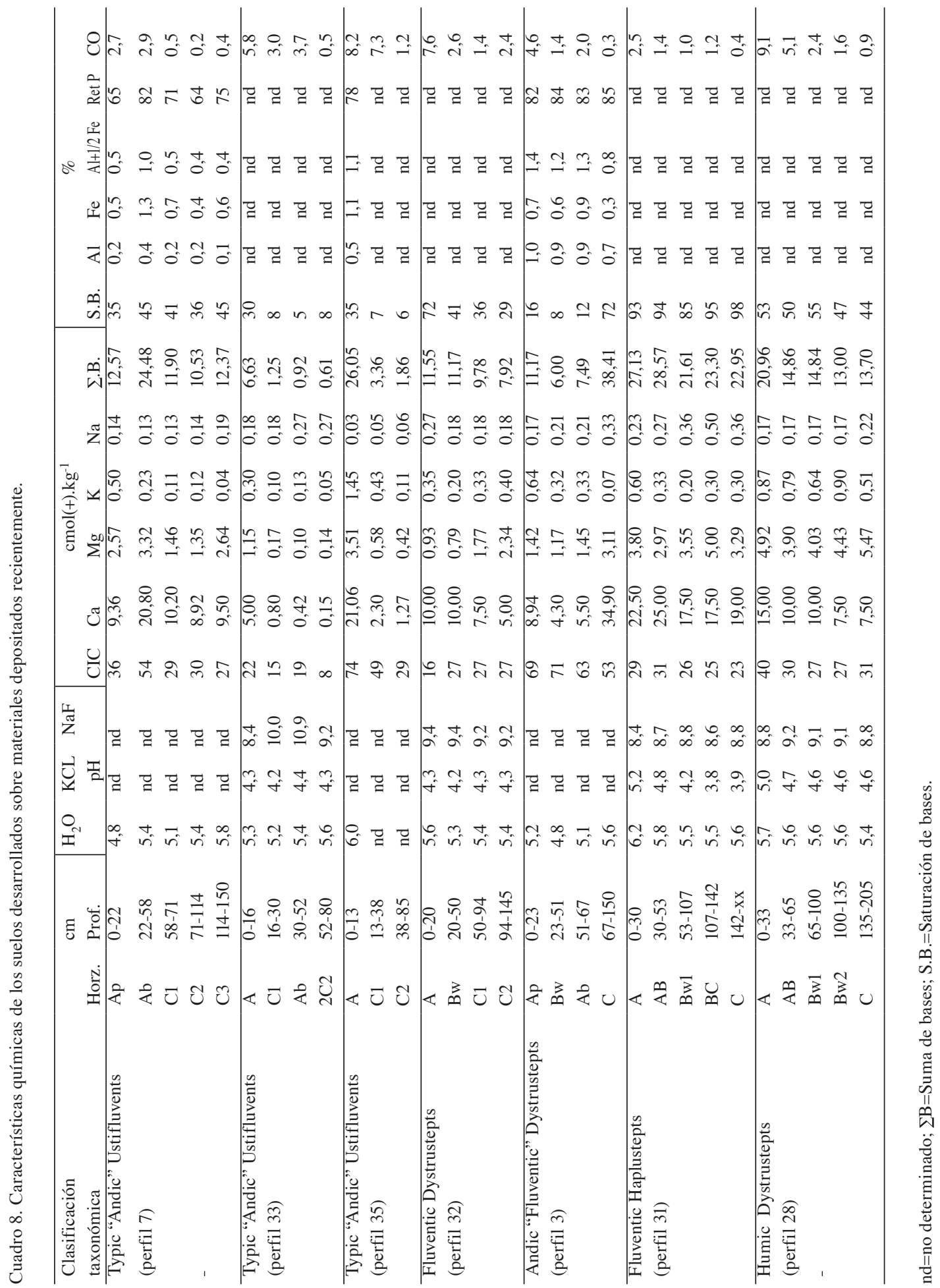




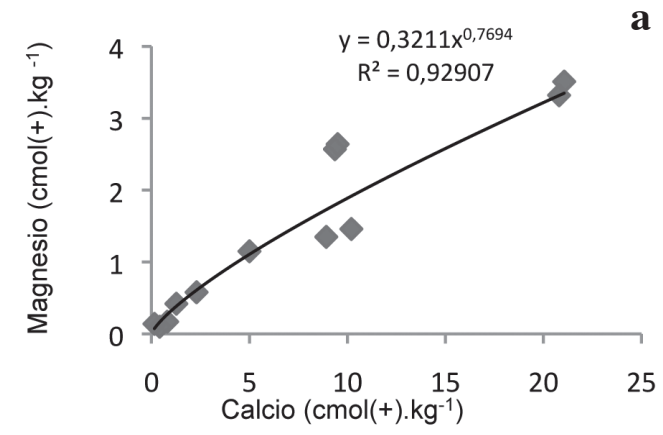

$\mathbf{a}$

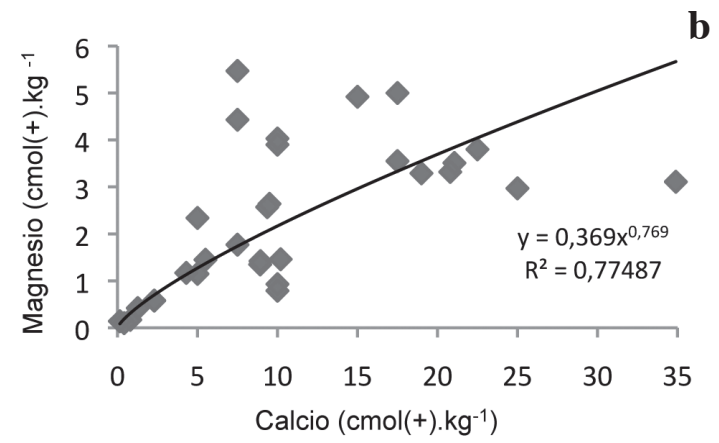

Fig. 7. Relación entre el calcio y el magnesio en suelos de origen aluvial en Santa María y Copey de Dota (a) Entísoles y (b) Entisoles e Inceptisoles.

los otros suelos de la unidad, los valores eran aún más bajos (Cuadro 8).

\section{Suelos desarrollados sobre materiales intrusivos ácidos}

1. Generalidades: La delimitación y caracterización de esta unidad se basó en fotointerpretación y descripción de 2 perfiles de suelo. El material parental son rocas intrusivas ácidas de la Cordillera de Talamanca, con una edad geológica estimada de 8 a 11 Ma (Kussmaul 1987) y una mineralogía primaria rica en cuarzo, plagioclasas sódicas y feldespatos potásicos (Drummond et al. 1995). Rocas intrusivas como la granodiorita, presenta contenidos importantes de cuarzo, plagioclasas sódicas, menor cantidad de feldespatos alcalinos y pequeñas cantidades de hornablenda y biotitas. Las monzodioritas presentan plagioclasas, poco feldespato potásico y menos de $5 \%$ de cuarzo. Las monzonitas tienen igual cantidad de feldespatos y plagioclasas con poco contenido de hornablenda y ó piroxenos (Le Maitre 2002). Las rocas resultantes del metamorfismo de contacto tienen composición silícea con contenido importante de óxidos de Fe y Mn. En esta unidad los suelos son superficiales a poco profundos, pardo amarillentos a amarillo parduzcos (Cuadro 9). Son de baja fertilidad y fuertemente ácidos, como lo indican los valores de $\mathrm{pH}, \mathrm{Al}$ intercambiable y saturación de acidez (Cuadro 10). Las texturas son moderadamente finas (franco arcillo arenoso, franco arcilloso), finas (arcilloso) y moderadamente gruesa (arena franca), con fragmentos rocosos angulosos; pueden tener horizontes de alteración hidrotermal en el subsuelo, carbón mineral cerca de la superficie (producto de incendios) y ceniza volcánica. Su relieve varía de fuertemente ondulado a escarpado (30-75\%) y su drenaje externo es rápido. A nivel de orden, clasifican como Entisoles con epipedón úmbrico y ócrico ó Inceptisoles, con un horizonte cámbico por lo general de un espesor delgado. Los Inceptisoles clasifican a nivel de

Cuadro 9. Clasificación de los suelos desarrollados sobre materiales intrusivos ácidos.

\begin{tabular}{|c|c|c|c|c|c|c|}
\hline \multirow{2}{*}{$\begin{array}{l}\text { Unidades cartográficas } \\
\text { (Símbolo) }\end{array}$} & \multicolumn{2}{|c|}{ Área } & \multicolumn{4}{|c|}{ Taxonomía } \\
\hline & ha & $\%$ & Orden & Suborden & Gran Grupo & Subgrupo \\
\hline \multicolumn{7}{|l|}{ Asociación } \\
\hline \multirow{2}{*}{$\begin{array}{l}\text { Intrusivos Ácidos } \\
\text { (IN) }\end{array}$} & 2190 & 12 & Entisol & Orthents & Ustorthents & Typic Ustorthents \\
\hline & & & Inceptisol & Ustepts & Dystrustepts & $\begin{array}{l}\text { Andic Dystrustepts } \\
\text { Typic Dystrustepts }\end{array}$ \\
\hline
\end{tabular}


Cuadro 10. Características morfológicas de los suelos desarrollados sobre intrusivos ácidos.

\begin{tabular}{lllll}
\hline $\begin{array}{l}\text { Clasificación } \\
\text { taxonómica }\end{array}$ & Horizonte & $\begin{array}{c}\text { cm } \\
\text { Prof. }\end{array}$ & & \\
\hline Andic Dystrustepts & $\mathrm{Ap}$ & $0-20$ & Pardo amarillento oscuro & 10 YR3/4 \\
(perfil 48) & $\mathrm{Bw}$ & $20-40$ & Pardo amarillento & 10 YR 5/8 \\
& 2BC & $40-70$ & Amarillo parduzco (30\%)* & 10 YR 6/8 \\
& $\mathrm{Cr}$ & $70-120$ & Pardo amarillento (45\%)** & 10 YR 5/8 \\
Typic Dystrustepts & $\mathrm{A}$ & $0-40$ & Rojo amarillento & 5 YR 4/6 \\
(perfil 16) & $\mathrm{Bw}$ & $40-115$ & Rojo amarillento & 5 YR 5/8 \\
& $\mathrm{C}$ & $115-210$ & Amarillo rojizo & 5 YR 6/8 \\
\hline
\end{tabular}

*Amarillo (10 YR 7/6 en30\%); pardo muy pálido (10 YR 8/1 en 20\%); blanco (10 YR 8/1 en 15\%); rojo (2,5 YR 4/8 en 5\%).

**Rojo oscuro (2,5 YR 4/8 en 45\%), pardo muy pálido (10 YR 8/2 en $10 \%$ ).

familia como Andic Dystrustepts, y como Typic Dystrustepts (Cuadro 9). Su principal uso son charrales y bosques intervenidos (helechos y Quercus sp).

2. Morfología: Los Andic Dystrustepts y Typic Dystrustepts son más desarrollados genéticamente, su morfología es $\mathrm{A} / \mathrm{Bw} / \mathrm{C}, \mathrm{A} /$ $\mathrm{Bw} / 2 \mathrm{BC} / \mathrm{Cr}$ (Cuadro 10). En general, el horizonte A puede tener $25 \mathrm{~cm}$ de grosor, color pardo amarillento, friable, adherente, plástico a no plástico. El horizonte $\mathrm{Bw}$ tiene espesores de 20 a $75 \mathrm{~cm}$; pardo amarillento (10 YR 5/8); con bloques de roca de hasta $20 \mathrm{~cm}$; estructura de bloques subangulares medianos y finos, moderada, ligeramente firme, muy adherente y muy plástico. Suele presentar un horizonte 2 BC, 20 a $30 \mathrm{~cm}$ de grosor; color variegado: amarillo parduzco (10 YR 6/8), amarillo (10 YR 7/6), blanco (10 YR 8/1), pardo muy pálido
(10 YR 8/3), rojo (2,5 YR 4/8), con bloques de roca alterada color amarillo rojizo (7,5 YR 6/8); estructura de bloques subangulares medianos y finos, débil a masiva, ligeramente firme y muy adherente y muy plástico. El horizonte $\mathrm{Cr}$ presenta guijarros alterados que se cortan con un cuchillo y ocupan un 30 a $40 \%$ dentro de una matriz arcillosa; color variegado: pardo amarillento (10 YR 5/8), rojo oscuro (2,5 YR 4/8), pardo muy pálido (10 YR 8/2); franco arcilloso, masivo, ligeramente firme, adherente y plástico (Figura 8 a-b). Esta unidad incluye los Typic Ustorthents que son los suelos de menor desarrollo edáfico encontrados en la región, su secuencia morfológica es tipo A/R (Figura $8 \mathrm{c}$ ).

En la Figura 9 se observa la distribución en la subcuenca, de los suelos asociados a litologias intrusivas. 


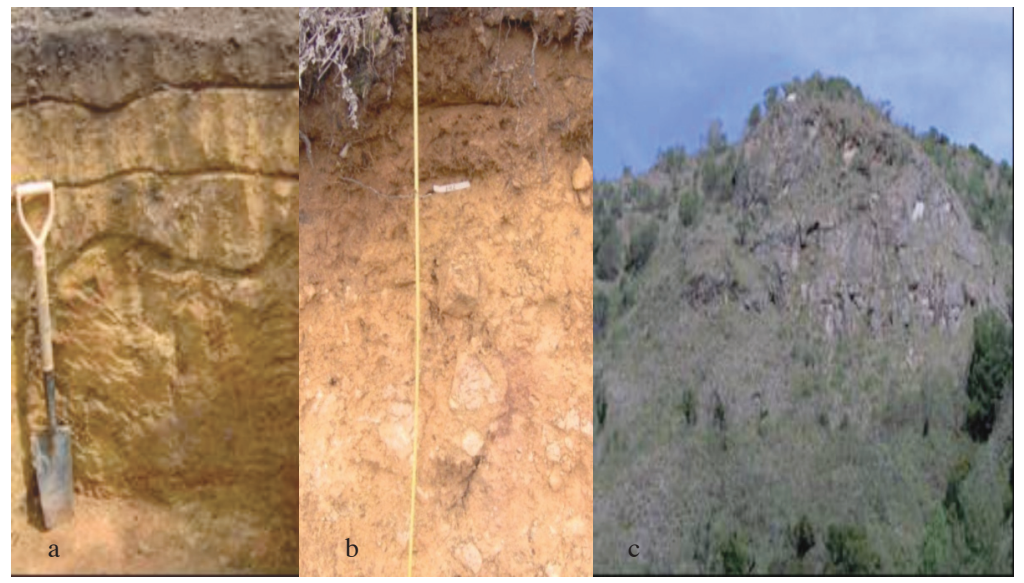

Fig. 8. Suelos desarrollados sobre materiales intrusivos ácidos. a. Perfil de suelo en Los Quemados de Dota: Andic Dystrustepts. b. Perfil de suelo en laderas al norte de Copey: Typic Dystrustepts. c. Cuerpo del intrusivo aflorando al norte de Santa María y Copey de Dota: Typic Ustorthents.

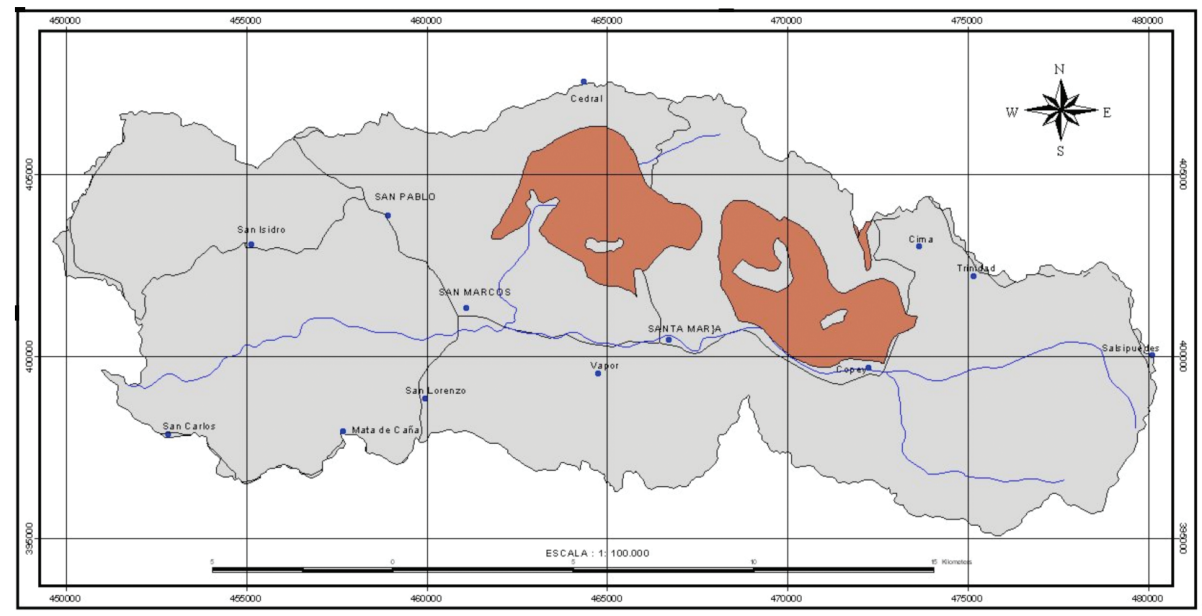

Fig. 9. Ubicación de suelos desarrollados a partir de materiales intrusivos.

3. Distribución del tamaño de partículas: Los Inceptisoles tienen por lo general, una cantidad importante de fragmentos rocosos angulosos, de algunos centímetros a metros de diámetro, tanto en la superficie como en todo el perfil de suelo. En el Cuadro 11 se observa que las texturas del horizonte A son moderadamente finas (franco arcillo arenosas y franco arcillosas) con porcentajes de arena ligeramente superiores que los de arcilla. Al aumentar la profundidad del suelo aumenta levemente los contenidos de arcilla y las texturas son moderadamente finas a finas (franco arcillo arenosa a arcillosa), en los horizontes $\mathrm{C}$ puede aumentar nuevamente el porcentaje de arena para tener textura moderadamente gruesa (arena franca).

4. Densidad aparente (Da): En el perfil de suelos numero 48, la $\mathrm{Da}\left(\mathrm{Mg} \cdot \mathrm{m}^{-3}\right)$ fluctúa entre 0,93 y 1,25 . El valor más bajo se presentó en el 
Cuadro 11. Características físicas de los suelos desarrollados sobre intrusivos ácidos.

\begin{tabular}{lclcccccccc}
\hline Clasificación & Horizonte & $(\mathrm{cm})$ & \multicolumn{3}{c}{ Textura $(\%)$} & & Clase & Mg.m ${ }^{-3}$ & Mg.m ${ }^{-3}$ & $\%$ \\
taxonómica & & Profund & Arena & Limo & Arcilla & textural & D. aparente & D. real & Porosidad \\
\hline Andic Dystrustepts & Ap & $0-20$ & 50,50 & 20,30 & 29,20 & FAa & 0,93 & 2,56 & 64,00 \\
(perfil 48) & Bw & $20-40$ & 47,70 & 24,30 & 28,00 & FAa & 1,00 & 2,77 & 64,00 \\
& 2BC & $40-70$ & 22,30 & 26,00 & 51,70 & A & 1,25 & 2,70 & 54,00 \\
& Cr & $70-120$ & 39,00 & 29,80 & 30,40 & FA & nd & nd & nd \\
\hline Typic Dystrustepts & A & $0-40$ & 33,00 & 23,00 & 44,00 & A & nd & 2,40 & nd \\
(perfil 16) & Bw & $40-115$ & 33,00 & 25,00 & 42,00 & A & nd & 2,70 & nd \\
& C & $115-210$ & 37,00 & 17,00 & 46,00 & A & nd & 2,50 & nd \\
\hline
\end{tabular}

horizonte superficial, lo que puede asociarse a mayor contenido de materia orgánica y a presencia de materiales derivados de ceniza volcánica. Valores más altos se hallaron en el subsuelo (1,00 y 1,25), con un mayor contenido de arcilla y menos materia orgánica (Cuadro 11).

5. Densidad real o de partículas (Dp): Se considera que los Inceptisoles en esta unidad son formados in situ y presentan una Dp $\left(\mathrm{Mg} . \mathrm{m}^{-3}\right)$ promedio de 2,61, con un máximo de 2,77 y mínimo de 2,40. Los valores más altos están relacionados con minerales de cuarzo, feldespatos y plagioclasas y los más bajos con la materia orgánica (Cuadro 11).

6. Porosidad: En el perfil 48, se encontró que la porosidad oscila entre 64 a $54 \%$ con ligeras variaciones en profundidad debido a los mayores contenidos de arcilla (Cuadro 11).

7. Acidez del suelo ( $\mathrm{pH}$ en $\mathrm{H}_{2} \mathrm{O}$, aluminio intercambiable y \% saturación de acidez): Las características mineralógicas del material parental y su meteorización imprimen a estos suelos propiedades ácidas. Con base en las calicatas 48 y 53 (Cuadro 12), ubicadas en esta unidad edáfica los suelos son extremadamente ácidos, con un pH en agua muy fuertemente ácido $(4,8-$ $4,9)$; aluminio intercambiable muy alto $(9,13 \mathrm{a}$ $\left.12,15 \mathrm{cmol}(+) \cdot 1^{-1}\right)$ y una saturación de acidez muy alta $(67$ a $93 \%)$.

8. Capacidad de Intercambio de cationes (CIC): La CIC obtenida por extracción con acetato de amonio $\left(\mathrm{NH}_{4} \mathrm{OAc} 1 \mathrm{~N}, \mathrm{pH}\right.$ $7)$, muestra valores que varían de mediana a baja en el perfil (16 a $\left.41 \mathrm{cmol}(+) \cdot \mathrm{kg}^{-1}\right)$, los valores más altos se encuentran en cerca de la superficie y se atribuyen a su mayor contenido de carbón orgánico como se observa en el horizonte Ap de la calicata 48 y perfil 16 (Cuadro 12).

9. Cationes intercambiables: Los suelos en esta unidad edáfica tienen bajo contenido de bases. La suma de bases es menor a $5 \mathrm{cmol}(+)$. $\mathrm{kg}^{-1}\left(0,7\right.$ a $\left.4,6 \mathrm{cmol}(+) \cdot \mathrm{kg}^{-1}\right)$ y saturación de bases menor a $13 \%$, por lo que los suelos se consideran como de baja fertilidad. Los niveles de cationes en superficie son muy bajos en $\mathrm{Ca}(2,00$ a 0,40 cmol(+). $\left.\mathrm{kg}^{-1}\right)$, medio bajo en $\mathrm{Mg}(1,04$ a 0,4 $\left.\mathrm{cmol}(+) \cdot \mathrm{kg}^{-1}\right)$, y bajos en $\mathrm{K}(0,16$ a $0,21 \mathrm{cmol}(+)$. $\left.\mathrm{kg}^{-1}\right)$. El fósforo es bajo en el horizonte superficial $\left(3 \mathrm{mg} \cdot \mathrm{l}^{-1}\right)$. Esto se explica por presencia de cuarzo, plagioclasas sódicas y feldespatos potásicos principalmente como minerales primarios de las rocas intrusivas ácidas, de alto contenido en sílice y sobre las cuales se han desarrollado estos suelos. 


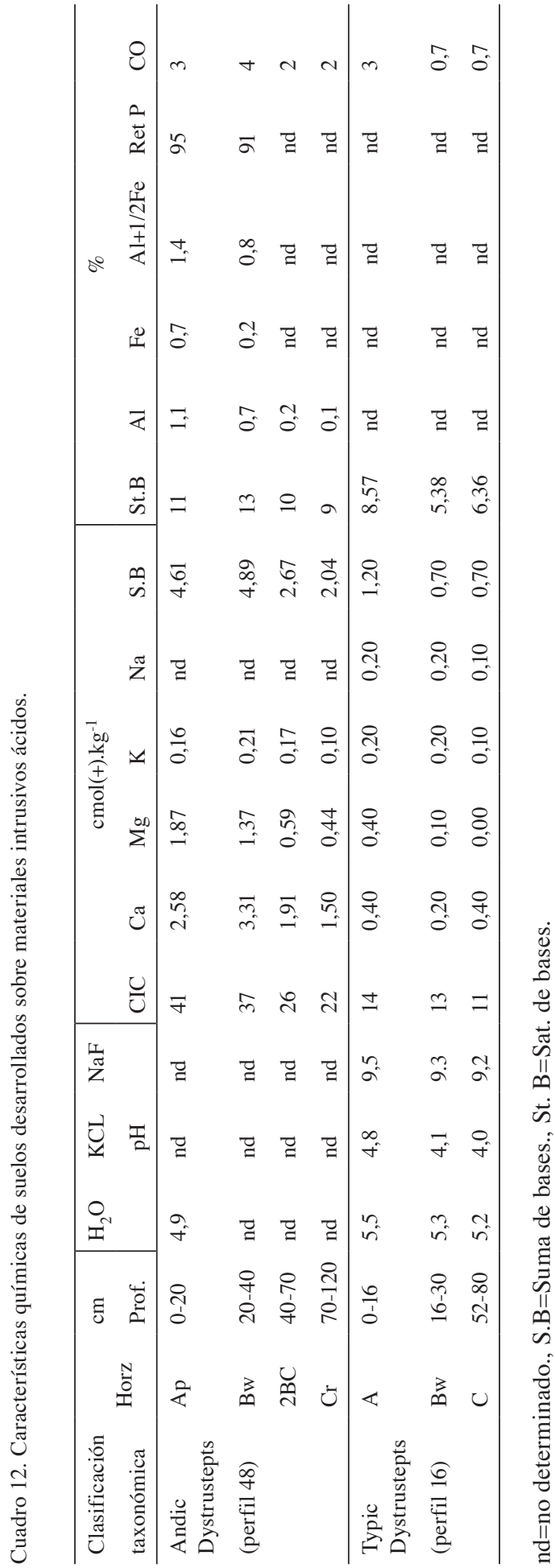

10. Porcentaje de retención de fósforo: Se encontró valores de retención de $\mathrm{P}$ que oscilan entre 91 y $95 \%$ en suelos que presentan horizontes con capas ándicas (Cuadro 12).

\section{CONCLUSIONES}

El viento del noreste, que circula dentro de la tropósfera en elevaciones de 1750 a 4000 m durante diciembre a febrero, es el subfactor del clima encargado de distribuir las cenizas sobre la Cordillera de Talamanca, por lo que los materiales originarios vendrían principalmente de la Cordillera Volcánica Central (macizos Irazú y Turrialba).

Los suelos derivados de cenizas volcánicas encontrados sobre la parte alta de la cuenca son el producto de procesos de andolización e hidromorfismo, pérdida de sílice y bases, así como de la formación de alófana, lo que da validez a la deposición de cenizas sobre la Cordillera de Talamanca, reportadas por varios autores.

Los horizontes superficiales de las áreas cartografiadas como suelos derivados de cenizas volcánicas realizadas a $2485 \mathrm{~m}$ de altura de la Cordillera de Talamanca, sugieren que las cenizas volcánicas que forman Andisoles y horizontes superficiales de los subgrupos "Andic" para Ultisoles, Inceptisoles y Entisoles de la región, son de una edad aproximada a 590 \pm 95 años.

Los horizontes B arcillosos del área son más antiguos. Al incrementarse la profundidad del perfil de suelo se pasa de $8620 \pm 140$ años (28$42 \mathrm{~cm}$ profundidad) a $20000 \pm 400$ años (183-187 $\mathrm{cm}$ de profundidad). La presencia de horizontes argílicos subyaciendo cenizas meteorizadas en la parte alta de la región estudiada, abre la posibilidad de una discontinuidad cronológica en el perfil de suelo.

Los suelos derivados de cenizas volcánicas de la región estudiada son frágiles y vulnerables a erosionarse y deslizarse. En general estos suelos son ácidos y con baja fertilidad, con excepción de una área cercana al poblado de Cañón y de otra cerca del camino que comunica la Cima con 
Copey de Dota donde se encontró un adecuado contenido de bases.

En general, los suelos desarrollados a partir de terrazas subrecientes son de poco desarrollo genético. Su principal factor formador es el material parental sobre el que ha intervenido el clima y el relieve, con procesos de remoción, desborde y deposición de materiales de las parte altas a los fondos de valle en un tiempo geológico reciente. La buena fertilidad de algunos suelos de las terrazas subrecientes es natural y se debe a la meteorización física que produce desprendimiento de partículas de litologías geológicas altas en bases, de las laderas al sur de Santa María y Copey de Dota, con su deposición en los fondos de valle.

Cerca de los materiales intrusivos de esta parte de la Cordillera de Talamanca, se formó una aureola de metamorfismo de contacto por el proceso de alteración hidrotermal de la roca preexistente y sobre los que se han desarrollado Inceptisoles. El material parental y el relieve han sido fundamentales como factores formadores de estos suelos. Sobre los intrusivos se encuentran Entisoles con muy escaso desarrollo genético (A/R). Los Inceptisoles se localizan en general, en relieves fuertemente ondulados, son pedregosos, poco profundos, ácidos y de coloraciones amarillentas. La granulometría del anillo alrededor de la roca intrusiva es fina (ICE 2002). Procesos de formación de suelos que han sucedido son la iluviación, lixiviación, lavado, formación de humus, descomposición, síntesis, erosión superficial.

\section{LITERATURA CITADA}

ALVARADO A., BERTSCH F., BORNEMISZA E., CABALCETA G., FORSYTHE W., HENRIQUEZ C., MATA R., MOLINA E., SALAS R. 2001. Suelos derivados de cenizas volcánicas (Andisoles) de Costa Rica. Asociación Costarricense de la Ciencia del Suelo. San José, Costa Rica. 111 p.

ALVARADO A., GLOBER N., OBANDO O. 1982. Reconocimiento de suelos de Puriscal-Salitrales y Tabarcia-San Ignacio de Acosta, pp. 102-118. In: El componente arbóreo en Acosta y Puriscal, Costa
Rica. ASCONA/CATIE/GTZ/MAG. Turrialba, Costa Rica.

BERGOEING J. 2007. Geomorfología de Costa Rica. Librería Francesa. San José. 328 p.

BLASER J., CAMACHO M. 1991. Estructura, composición y aspectos silviculturales de un bosque de robles (Quercus spp.) del piso montano en Costa Rica. Proyecto CATIE/COSUDE, Colección Silvicultura t Manejo de Bosques Naturales N ${ }^{\circ}$. 1. Turrialba, Costa Rica. 68 p.

BUOL S.W., HOLE F.D., McCRAKEN R.J. 1989. Soil genesis and classification. $3^{\text {rd }}$ ed. Iowa State University Press, Ames. USA. 446 p.

CUBERO D.A. 2002. Estudio semidetallado de suelos y clasificación de tierras de la cuenca del río Savegre. MAG, Dpto. Evaluación de Suelos y Tierras. San José, Costa Rica. 61 p.

CHINCHILLA M., ALVARADO A., MATA R. 2011a. Factores formadores y distribución de suelos en la subcuenca del río Pirrís, Talamanca, Costa Rica. Agronomía Costarricense. 35(1): 33-57.

CHINCHILLA M., MATA R., ALVARADO A. 2011b. Caracterización y clasificación de algunos ultisoles de la región de los Santos, Talamanca, Costa Rica. Agronomía Costarricense. 35(1): 59-81.

DENYER P., ARIAS O. 1991. Estratigrafía de la región central de Costa Rica. América Central. Revista Geológica de América Central 12:1-59.

DRUMMONT M.K., BORDELON M., de BOER J.Z., DEFANT M.J., BELLON H., FEIGENSON M.D. 1995. Igneous petrogenesis and tectonic setting of plutonic and volcanic rocks of the Cordillera de Talamanca, Costa Rica-Panamá, Central American Arc. American Journal of Science 295:875-919.

DRUMMONT M.K., BORDELON M., de BOER J.Z., DEFANT M.J., BELLON H., FEIGENSON M.D., DRIESE S.G., ORVIS K.H., HORN S.P., LI Z., JENNINGS D.S. 2007. Paleosol evidence for Quaternary uplift and the climate and ecosystem changes in the Cordillera de Talamanca, Costa Rica. Paleogeography, Paleoclimatology, Paleoecology 248:1-23.

FASSBENDER H. 1980. Química de Suelos. IICA. San José, Costa Rica. 396 p. 
GÓMEZ O., CHINCHILLA M. 2005. Estudio taxonómico y mineralógico de los suelos de la cuenca del río Térraba. MAG/ICE. San José, Costa Rica. 233 p.

HARRIS S.A. 1971a. Podsol development on volcanic ash deposits in the Talamanca range, Costa Rica, pp. 191209. In: Paleopedology: origin, nature and dating of paleosols. Halsted Press. New York, USA.

HARRIS S.A. 1971b. Quaternary vulcanicity in the Talamanca range of Costa Rica. Canadian Geographer 15(2):141-145.

HOLDRIDGE L.R., GRENKE W.C., HATHEWAY W.H., LIANG T., TOSI J. 1971. Forest environments in tropical life zones: a pilot study. New York, USA. v. I, p. 1-397; v. II, pp. 398-747.

HORN S. 1990. Timing of deglaciation in the Cordillera de Talamanca. Climate Research (1):81-83.

HORN S.P., SANDFORD R.L. 1992. Holocene fires in Costa Rica. Biotrópica 24(3):354-361.

ICAFE (Instituto del Café de Costa Rica), CIA (Centro de Investigaciones Agronómicas). 2000. Caracterización de suelos cafetaleros en la región de los Santos. En prensa.

ICAFE (Instituto del Café de Costa Rica). 2002. Caracterización de suelos y cultivo de café en el cantón de Pérez Zeledón. Heredia, CR. 101 p.

ICE (Instituto Costarricense de Electricidad). 1979. Regional Geology Boruca Project. San José, CR, Departamento de Geología. 7 p.

ICE (Instituto Costarricense de Electricidad). 2002. Proyecto Hidroeléctrico Pirrís: Sitio de Presa. San José, CR, UEN PSA. v.1. 213 p.

ICE (Instituto Costarricense de Electricidad). 2006. Informe de Hidrología. Comisión de manejo de sedimentos de Pirrís. San José, CR, UEN PSA. 8 p.

ICE (Instituto Costarricense de Electricidad). 2007. Estudio de amenazas naturales y antrópicas en la cuenca del río Pirrís. San José, CR, UEN PSA. 83 p.

KAPPELLE M., van UFFELEN J.G. 2005. Los suelos de los páramos de Costa Rica, pp. 147-159. In: Páramos de Costa Rica. Instituto nacional de Biodiversidad. Santo Domingo de Heredia, Costa Rica.

KUSSMAUL S. 1987. Petrología de las rocas intrusivas neógenas de Costa Rica. Rev. Geol. Amer. Central 7:83-111.
LACHNIET M. 2001. Quaternary geology and paleoclimate of Costa Rica: Evidence from glaciations, stable isotopes of surface water, and speleothem. Tesis Ph.D in Earth Sciences. Michigan State University, U.S. 140 p.

LACHNIET M., VAZQUEZ L. 2005. Last glacial maximun equilibrium lines altitudes in the circun Caribbean (México, Guatemala, Costa Rica, Colombia and Venezuela). Quaternary International 138-139:129-144.

LANDAETA A. 1977. Caracterización de la fracción mineral y determinación del ZPC de una catena de suelos derivados de cenizas volcánicas de la Cordillera de Talamanca. Tesis de licenciatura, Universidad de Costa Rica, San José, Costa Rica. 90 p.

LANDAETA A., LÓPEZ C.A., ALVARADO A. 1978. Caracterización de la fracción mineral de suelos derivados de cenizas volcánicas de la Cordillera de Talamanca, Costa Rica. Agronomía Costarricense 2(2):117-129.

Le MAITRE R.W 2002. Igneous rocks: a classification and glossary of terms. 2 ed. Cambridge Universty Press. $236 \mathrm{p}$.

LÓPEZ H. 1978. Caracterización de la fracción mineral de cinco Andepts de los cantones de Corredores y Coto Brus. Tesis de licenciatura, Universidad de Costa Rica, San José, Costa Rica. 51 p.

MATA R., RAMÍREZ J.E. 1999. Estudio de caracterización de suelos y su relación con el manejo del cultivo de café en la Provincia de Heredia. ICAFE. San José, Costa Rica. 92 p.

MORA S. 1979. Estudio Geológico de una parte de la Región Sureste del Valle del General Provincia de Puntarenas Costa Rica. Tesis de licenciatura, Universidad de Costa Rica, San José, Costa Rica. $184 \mathrm{p}$.

MORA S., VALVERDE R., BRENES G. 1985. Análisis geológico-geomorfológico de la Cuenca del río Pirrís (Parrita). Cartago, CR, ITCR. 44 p.

ORVIS K., HORN S. 2000. Quaternary glaciers and climate on Cerro Chirripó, Costa Rica. Quaternary Research 54:24-37.

OTÁROLA C.E., ALVARADO A. 1976. Caracterización y clasificación de algunos suelos del Cerro de la Muerte, Talamanca, Costa Rica. Suelos Ecuatoriales 8(1):397-400. 
PORTA J., LOPEZ-ACEVEDO M., ROQUERO C. 1994. Edafología para la agricultura y el medio ambiente. Ediciones Mundi-Prensa. España. 807 p.

SANCHO F., NÚÑEZ J. 1985. Estudio de suelos. Secciones I y II de la Cuenca del Río Parrita. San José, CR, UCR. 167 p.

SOIL SURVEY STAFF 2006. Soil Taxonomy: A basic system of soil classification for making and interpreting soil surveys. Tenth ed. Washington DC, USDA. $341 \mathrm{p}$.

SOLÓRZANO J.A. 1997. Evaluación de enmiendas orgánicas en el cultivo de la mora silvestre cv Vino (Rubus praecipuus) Bailey, en la Cima de Dota, San José, Costa Rica. Tesis de licenciatura, Universidad de Costa Rica, San José, Costa Rica. 107 p.

USDA-NRCS (National Soil Survey Center; Natural Resource Conservation Service; US Departament of Agriculture). 2002. Field book for describing and sampling soils. Lincoln, Nebraska, USA. s.p.

van UFFELEN J.G. 1993. A gelogical, geomorphological and soil transect study of the Chirripó massif and adjacent areas, Cordillera de Talamanca, Costa
Rica. Tesis de Maestría, Wageningen University, Wageningen. $72 \mathrm{p}$.

WEYL R. 1957. Excursiones geológicas en Costa Rica: vestigios de los glaciares del Pleistoceno. Instituto Geográfico Nacional. San José, Costa Rica. 50 p.

WIDMER Y. 1999. Soil characteristics and Chusquea bamboos in the Quercus forests of the Cordillera de Talamanca, Costa Rica, pp. 63-83. In: Y. Widmer. The ecological role of bamboo (Chusquea spp.) in the old-growth Quercus forests of the Cordillera de Talamanca, Costa Rica. ETH Nr. 13186. Zürich University. Chapter 3.

WINOWIECKI 1. 2008. Soil biochemical patterns in the Talamanca foothills, Costa Rica: local knowledge and implications for agroecosystems. Ph.D. Thesis. University of Idaho/Centro Agronómico Tropical de Investigación y Enseñanza. USA. $172 \mathrm{p}$.

WILLIAMSON G.B., SCHATS G.E., ALVARADO A., REDHEAD C.S., STERNER R.W. 1986. Effects of repeated fire on tropical paramo vegetation. Tropical Ecology 27(1):62-69. 
